\title{
RESPONSABILIDAD POR PRODUCTOS DEFECTUOSOS* Reflexiones en torno a la carga de la prueba
}

\author{
Ricardo de Angel Yágüez \\ Catedrático de Derecho civil de la Universidad de Deusto
}

Sumario: I. Objeto y propósito de esta ponencia. A) Rasgos principales de la Ley. B) Orientación de esta ponencia. II. Reflexiones en torno a la prueba en la Ley de 6 de julio de 1994. A) Consideraciones generales. a) Principios que adopta la Ley. b) El régimen de la prueba en esta Ley. c) Lo que el perjudicado no tiene que probar. d) El «cruce» de las reglas sobre la carga de la prueba. Doctrina del Tribunal Supremo sobre flexibilidad del principio «incumbit probatio». La «facilidad» $\mathrm{o}$ «disponibilidad» para cada parte, a efectos de prueba. e) Aspectos probatorios que la norma no contempla. i) Una «prueba» previa: la de la procedencia del producto, esto es, la de la identidad del fabricante. ii) El caso del producto defectuoso cuyo concreto fabricante no consta, siendo seguro que es uno de entre varios posibles. Hipótesis que caben. Cuando el perjudicado no puede establecer la identidad del concreto fabricante: «market share liability» y doctrina del daño causado por el miembro indeterminado de un grupo. iii) Prueba de la identidad del fabricante del bien «unido o incorporado» a otro bien y de la del fabricante del «elemento integrado en un producto terminado». B) La prueba del defecto. a) Observaciones previas. La amenazadora apariencia de esta carga probatoria. b) Interpretación que procede. c) Relación con el artículo 3. d) La prueba del defecto de diseño: la «perfección posible». e) La prueba del defecto de información. C) La prueba de la relación de causalidad. a) La «reducción» del problema de la causalidad al modelo estadístico: la teoría del «more probable than not». b) Limitaciones del criterio de la probabilidad estadística. c) La relación de causalidad cuando se trata de un «defecto» en la información por parte del fabricante.

* Una síntesis de este texto fue expuesta por el autor en el II Congreso Internacional de Derecho de daños, celebrado en la Facultad de Derecho y Ciencias Políticas de la Universidad de Lima durante los días 16 a 19 de setiembre de 1996. 


\section{Objeto y propósito de esta ponencia}

La primera de mis intervenciones en este Congreso (en el que participo honradísimo y merced a la benevolencia y al sentido de la amistad del profesor Fernández Sessarego) va a versar sobre algunos aspectos que ofrece la Ley española sobre responsabilidad civil por los daños causados por productos defectuosos, que fue promulgada el 6 de julio de 1994 y entró en vigor el siguiente día 8.

\section{A) Rasgos principales de la Ley}

Esta Ley tuvo por objeto llevar a cabo la adaptación del Derecho español a la Directiva sobre la materia de la entonces Comunidad Económica Europea, de 25 de julio de 1985. Se promulgó con un considerable retraso respecto al plazo de tres años que al efecto había establecido la norma comunitaria y su redacción fue objeto de un largo y complejo proceso de elaboración, debido en buena parte a las discrepancias doctrinales planteadas al respecto.

Esta Ley, como corresponde a su naturaleza, recoge los principios y criterios de la Directiva comunitaria, que luego mencionaré.

Mi propósito es el de suscitar algunas cuestiones que la Ley plantea, en torno a un punto muy definido (aunque de amplio espectro) como es el relativo a la carga de la prueba. No obstante, considero oportuno resumir los principales rasgos de la Ley en cuestión. Pueden formularse así:

1. Se instaura un régimen de responsabilidad objetiva, aunque no absoluta, como puntualiza la exposición de motivos de la Ley.

Es responsabilidad objetiva, porque el fabricante responde - como establece el artículo 1- de los daños causados por los defectos de los productos que fabrique. No hay ninguna alusión a la culpa, lo que significa que el criterio de imputación no es ella, sino la efectiva producción del daño.

No obstante, la responsabilidad objetiva no es absoluta, porque el fabricante se ve exonerado de responsabilidad si prueba cualquiera de las circunstancias del artículo 6, esto es:

a) Que no había puesto en circulación el producto.

b) Que, dadas las circunstancias del caso, es posible presumir que el defecto no existía en el momento en que se puso en circulación el producto.

c) Que el producto no había sido fabricado para la venta o cualquier otra forma de distribución con finalidad económica, ni fabricado, importado, suministrado o distribuido en el marco de una actividad profesional o empresarial. 
d) Que el defecto se debió a que el producto fue elaborado conforme a normas imperativas existentes; $y$, por fin,

e) Que el estado de los conocimientos científicos y técnicos existentes en el momento de la puesta en circulación no permitía apreciar la existencia del defecto. Esta última causa de exoneración de responsabilidad, sin embargo, no es aplicable en el caso de medicamentos, alimentos o productos alimentarios destinados al consumo humano.

He de señalar que hasta ahora, para simplificar, me he referido exclusivamente al fabricante (como lo haré de ahora en adelante), pero no sin dejar de advertir que el «principio general» del artículo 1 de la Ley incluye a los fabricantes y a los importadores. A este respecto, téngase presente que el apartado 1 del artículo 4 determina el alcance del concepto de «fabricante», a efectos de esta Ley, incluyendo al que lo es del producto terminado, al de cualquier elemento integrado en un producto terminado, al que produce una materia prima e incluso a cualquier persona que se presente al público como fabricante, poniendo su nombre, denominación social, marca o cualquier otro signo o distintivo en el producto $o$ en el envase, en el envoltorio o en cualquier otro elemento de protección o de presentación.

El apartado 2 del mismo artículo 4 dice que se entiende por importador quien, en el ejercicio de su actividad empresarial, introduce un producto en la Unión Europea para su venta, arrendamiento, arrendamiento financiero o cualquier otra forma de distribución.

Y no sólo eso, sino que la Ley va más lejos, puesto que el apartado 3 del mismo artículo dispone que si el fabricante del producto no puede ser identificado, será considerado como fabricante quien hubiere suministrado o facilitado el producto, a menos que, dentro del plazo de tres meses, indique al perjudicado la identidad del fabricante o de quien le hubiera suministrado o facilitado a él dicho producto. Regla que es de aplicación en el caso de un producto importado, si el producto no indica el nombre del importador, aun cuando se indique el del fabricante.

Pero, como decía antes, en mi exposición utilizaré normalmente la sola expresión de «el fabricante».

2. Otra particularidad de la Ley consiste en la delimitación de su «ámbito de protección», puesto que el régimen de responsabilidad previsto en la misma comprende los supuestos de muerte y las lesiones corporales, así como los daños causados en cosas distintas del propio producto defectuoso, siempre que la cosa dañada se halle objetivamente destinada al uso o consumo privados y en tal concepto haya sido utilizada principalmente por el perjudicado. En este último caso se deducirá una franquicia de 65.000 pesetas. 
Por tanto, los demás daños y perjuicios, incluidos los daños morales, como puntualiza el artículo 10.2, quedan excluidos del ámbito de la Ley, aunque podrán ser resarcidos conforme a la legislación civil general.

3. Las personas responsables del mismo daño por aplicación de la Ley lo serán solidariamente (artículo7).

4. Según el artículo 8, la responsabilidad del fabricante o importador no se reducirá cuando el daño sea causado conjuntamente por un defecto del producto y por la intervención de un tercero. No obstante, el sujeto responsable, de acuerdo con la Ley, que hubiera satisfecho la indemnización podrá reclamar al tercero la parte que corresponda a su intervención en la producción del daño.

5. Sin embargo, la culpa del perjudicado (o de una persona de la que éste deba responder civilmente) puede ser causa de exención o reducción de la responsabilidad del fabricante, si el daño causado fuera debido conjuntamente a un defecto del producto y a aquella culpa (artículo 9).

6. Otra regla digna de mención es la del artículo 15 , por cuya virtud las acciones reconocidas en la Ley no afectan a otros derechos que el perjudicado pueda tener como consecuencia de la responsabilidad contractual o extracontractual del fabricante.

7. Se establece, para la prescripción de la acción de reparación de los daños y perjuicios previstos en la Ley, un plazo hasta ahora desconocido en el Derecho español, es decir, el de tres años, inferior al común de la responsabilidad contractual (quince años) y superior al de la responsabilidad extracontractual (un año). El plazo se computa desde la fecha en que el perjudicado sufrió el perjuicio, ya sea por defecto del producto o por el daño que dicho defecto le ocasionó, siempre que se conozca al responsable de dicho perjuicio. Así lo dispone el artículo 12.

Por otro lado, el artículo 13 establece una forma de extinción de la responsabilidad por el paso del tiempo, ya que los derechos reconocidos al perjudicado en esta Ley se extinguirán transcurrido ese término, a contar desde la fecha en que se hubiera puesto en circulación el producto concreto causante del daño; a menos que durante ese período se hubiese iniciado la correspondiente reclamación judicial (artículo 13).

8. Conforme al artículo 14, son ineficaces frente al perjudicado las cláusulas de exoneración o limitación de la responsabilidad civil prevista en la Ley.

9. Todo ello, por otra parte, sobre la base del ámbito objetivo de tutela que viene dado por el artículo 2, al definir el «concepto legal de producto». Se dice en ese lugar que, a los efectos de esta Ley, se entiende 
por producto todo bien mueble, aun cuando se encuentre unido o incorporado a otro bien mueble o inmueble, excepto las materias primas agrarias y ganaderas y los productos de la caza y de la pesca que no hayan sufrido transformación inicial. El apartado 2 del mismo artículo dispone que se consideran productos el gas y la electricidad.

10. La responsabilidad deriva de haber puesto en circulación el producto defectuoso que causó el daño, motivo por el que la Ley (artículo 3) se cuida de definir qué se entiende por tal. Dice ese precepto:

«1. Se entenderá por producto defectuoso aquel que no ofrezca la seguridad que cabría legítimamente esperar, teniendo en cuenta todas las circunstancias y, especialmente, su presentación, el uso razonablemente previsible del mismo y el momento de su puesta en circulación.»

De otro lado, los apartados 2 y 3 del mismo artículo rezan así:

«2. En todo caso, un producto es defectuoso si no ofrece la seguridad normalmente ofrecida por los demás ejemplares de la misma serie.

3. Un producto no podrá ser considerado defectuoso por el solo hecho de que tal producto se ponga posteriormente en circulación de forma más perfeccionada.»

Hecho este resumen de la Ley, no está de más señalar que, probablemente, su régimen de responsabilidad no mejora de forma sensible - en lo que se refiere a la tutela del perjudicado- el existente con anterioridad en España. La Ley aplicable era la general para la defensa de los consumidores y usuarios, de 19.7.84, cuyo artículo 25 establece una inversión de la carga de la prueba muy favorable para el consumidor o usuario y cuyo artículo 28 dispone, según opinión mayoritaria, un sistema de responsabilidad objetiva para determinados bienes y servicios, entre los que se mencionan, a título meramente enunciativo, los productos alimenticios, los de higiene y limpieza, cosméticos, especialidades y productos farmacéuticos, servicios sanitarios, de gas y electricidad, electrodomésticos y ascensores, medios de transporte, vehículos a motor y juguetes y productos dirigidos a los niños.

Dictada la Ley de 1994, la de 1984 ve limitado su ámbito a los daños causados por servicios y a los derivados de bienes que no merezcan la calificación de «producto» a efectos de la nueva normativa.

\section{B) Orientación de esta ponencia}

Como decía antes, mi propósito ahora es el de analizar un aspecto determinado de la Ley española: el que se refiere a la prueba a cargo del perjudicado. 
Es el artículo 5 el que se ocupa de este extremo, con el siguiente texto:

«El perjudicado que pretenda obtener la reparación de los daños causados tendrá que probar el defecto, el daño y la relación de causalidad entre ambos.»

He elegido este enfoque por varios motivos:

En primer lugar, porque la prueba es - a mi juicio- la clave de cualquier sistema legal en materia de responsabilidad civil por productos. En otras palabras, porque participo de la opinión, insistentemente expresada por los estudiosos del llamado «Derecho del consumo», de que las cuestiones procesales tienen gran importancia dentro de la responsabilidad civil del fabricante ${ }^{1}$.

En segundo término, porque tomar como perspectiva la prueba (a pesar del carácter adjetivo que habitualmente la atribuimos) es una forma de contemplar la Ley entera; esto es, en sus aspectos más rigurosamente sustantivos.

Por fin, porque parece claro que la Directiva (en su artículo $4^{2}$ ) no quiso interferir en los ordenamientos jurídicos nacionales más que en lo que respecta al onus probandi a cargo del perjudicado; esto es, no en lo relativo a los medios de prueba y su valoración. Lo que significa que estamos en presencia del extremo en que el Derecho de cada Estado de la Unión Europea queda más libre del objetivo armonizador que la Directiva persiguió.

Dicho todo esto, paso al análisis del tema propuesto.

\section{Reflexiones en torno a la prueba en la Ley de 6 de julio de 1994}

Divido mi exposición en tres capítulos. De un lado, el constituido por observaciones de carácter general en torno al régimen probatorio en la Ley. De otra parte, los que se refieren a la prueba de los dos extremos que más dificultades plantean: el defecto y la relación de causalidad.

1 Hasta el punto de que una de las razones de las orientaciones doctrinales y jurisprudenciales que han llevado al régimen instaurado por la Directiva ha sido precisamente la de «organizar» de forma adecuada el sistema probatorio, mediante un reparto equitativo de la carga de la prueba entre el fabricante y el perjudicado. Así se expresó en nuestra doctrina, antes de la Ley que nos ocupa, Alcover Garau (La responsabilidad civil del fabricante, Madrid: Civitas, 1990, p. 128). PARRA LUCÁN, Daños por productos y protección del consumidor, Barcelona: José María Bosch Editor, 1990, p. 533, señala que con la regla de la Directiva sobre carga de la prueba se pretende liberar a los fabricantes de procesos injustificados emprendidos por las víctimas de cualesquiera accidentes, con independencia de que pudiera o no reconducirse al fabricante la causa del daño. Y ello, en contra de la postura enérgicamente defendida a lo largo del proceso de elaboración de la Directiva por los representantes de los consumidores, en el sentido de invertir la carga de la prueba.

2 «El perjudicado deberá probar el daño, el defecto y la relación causal entre el defecto y el daño.» 


\section{A) Consideraciones generales}

a) Principios que adopta la Ley

i) De acuerdo con el régimen general de responsabilidad, la novedad introducida por el artículo 5 en materia probatoria puede no ser muy significativa en la práctica, porque con independencia de esta Ley juega hoy en favor del perjudicado la presunción de culpa del agente, circunstancia que hace muy difícil para este último liberarse de responsabilidad. No obstante, desde el punto de vista conceptual sí es considerable el significado del sistema probatorio que la Ley establece, porque el principio de responsabilidad objetiva que introduce significa, no ya que la culpa se presume, sino que, simplemente, no se tiene en cuenta. Con el régimen de esta Ley, no es necesario que el perjudicado pruebe la culpa del fabricante y éste tampoco puede verse libre de responsabilidad (salvo en los casos que diré) probando que no ha habido culpa por su parte. Procede señalar que precisamente el objetivo de liberar al perjudicado de «la improcedencia y la sustancial injusticia» que constituye someter su reparación a lo que en punto a la culpa del fabricante se pruebe es lo que constituye la médula de las orientaciones doctrinales modernas en materia de responsabilidad por productos y, por tanto, la clave de la Directiva y de nuestra Ley ${ }^{3}$.

En STAPLETON ${ }^{4}$ se explica la evolución experimentada en este punto en el Derecho norteamericano, antecedente del sistema de la Directiva. Menciona, como significativo en la tendencia judicial «pro demandante», el caso Barker v. Lull Engineering Co., en el que el Tribunal Supremo de California adoptó un criterio de dos vías en relación con un presumible

3 Alcover Garau, «La responsabilidad civil del fabricante», en Cuadernos de Derecho judicial, XIX, Madrid: Consejo General del Poder Judicial, 1993, p. 269, señala que en un régimen basado en la responsabilidad objetiva, el consumidor no se ve libre de toda carga de prueba, sino que debe probar cuatro extremos fundamentales: el daño, el defecto, el nexo causal entre ambos y el nexo causal entre el defecto y el proceso productivo, o sea, que el defecto es imputable al fabricante y no a otro. En un régimen de responsabilidad basado en la idea de la culpa — añade el autor - se debería probar un quinto extremo: la negligencia del fabricante. Estamos de acuerdo con estas apreciaciones, aunque la alusión al nexo entre el defecto y el proceso productivo podría ser desorientadora si no se entendiese lo que el autor quiere decir; esto es, que corre a cargo del perjudicado la prueba de la identidad del concreto fabricante del producto que le causó el daño. En la doctrina italiana, CENDON y ZIviz, «L'inversione dell' onere della prova nel diritto civile», en La responsabilità extracontrattuale, Milán: Giuffrè, 1994, p. 154, advierten que el artículo 8 de la Ley italiana de transposición (equivalente a nuestro artículo 5) excluye, de una vez por todas, la necesidad de probar la culpa del fabricante por parte del consumidor. Así se ve robustecida una orientación jurisprudencial que, desde hace ya veinte años, venía estableciendo para estos casos una presunción de culpa a cargo del fabricante.

${ }^{4}$ Stapleton, Product Liability, Londres: Butterworths, 1994, pp. 264-265. 
defecto de diseño: el producto es defectuoso bien porque deja de ofrecer la seguridad que un consumidor ordinario podría esperar de él al usarlo de una manera previsiblemente deseable o razonable (la vía de «las expectativas del consumidor»), o bien porque los riesgos inherentes al diseño no están justificados por los beneficios intrínsecos del mismo (la vía del principio «riesgo/utilidad»). Por medio de este razonamiento se llegó a una significativa reconsideración de la carga de la prueba: una vez que el demandante prueba que el diseño del producto fue la causa del daño, eso crea una presunción (aunque rebatible) de que el diseño es defectuoso a la luz del criterio «riesgo/utilidad», siendo entonces el demandado el que tiene que demostrar que el producto no era defectuoso. Los argumentos en favor de este traslado de la carga de la prueba al demandado son varios y entre ellos está el de sus mejores condiciones para acceder al conocimiento de información significativa en materia de costes y beneficios; por eso, en el caso Barker el demandante ni siquiera tuvo que probar la existencia del defecto ${ }^{5}$.

ii) En todo caso, lo que interesa advertir es que ahora el demandante no tiene que probar quién causó el defecto, del mismo modo que no asiste al fabricante el argumento (ni la prueba) de que él no fue el que produjo ese defecto.

\section{b) El régimen de la prueba en esta Ley}

Procediendo de mayor a menor, lo primero que debe advertirse es que corresponde al fabricante la prueba de cualquiera de las causas de exoneración de responsabilidad que enumera el artículo 6. El párrafo primero del apartado 1 de este artículo 6 lo dice expresamente: «El fabricante o el importador no serán responsables si prueban...»

Por lo que se refiere al fabricante de una parte integrante de un producto terminado, también le corresponde, para quedar excluido de responsabilidad, probar que el defecto es imputable a la concepción del producto al que la parte integrante ha sido incorporada o a las instrucciones dadas por el fabricante de ese producto. "Si prueban» son palabras que al efecto aparecen en el apartado 2 del artículo 6.

5 A partir de esta resolución, combinadas la dificultad del demandado de probar un hecho negativo y la resistencia de muchos tribunales a dictar sentencias absolutorias, aunque los demandados adujeran pruebas abrumadoras, el resultado fue el aumento de esperanzas de éxito en reclamaciones basadas en defectos relacionados con el diseño. STAPLETON parece establecer en este punto una comparación entre la línea jurisprudencial norteamericana y la de la Directiva en perjuicio de esta última, en el sentido de que en ella el demandante todavía tiene sobre si la «a menudo onerosa carga de probar que el producto era defectuoso»; pero acaso sea porque la autora hace una inadecuada interpretación de lo que en realidad significa (en la Directiva) «probar el defecto». 
También corresponde al fabricante (a efectos de reducirse o suprimirse su responsabilidad, artículo 8) probar que el daño causado fue debido conjuntamente a un defecto del producto y a culpa del perjudicado o de una persona de la que éste deba responder civilmente. Hay que hacer notar, sin embargo, que esta carga probatoria del fabricante podrá verse en muchos casos compensada por la que incumbe al perjudicado de demostrar la relación de causalidad, en la medida en que este concepto entraña la puesta en conocimiento (eso es probar) de hechos que muy frecuentemente pueden revelar la eventual culpa del perjudicado o de quien éste debe responder.

Por supuesto, corresponde al fabricante la prueba del transcurso del plazo de prescripción del artículo 12.1, en virtud del juego de la prescripción ope exceptionis. Pero la prueba de la interrupción de la prescripción (artículo 12.2) será de cargo del perjudicado que la alegue (artículo 1.214 del Código civil).

Es también del fabricante la prueba del transcurso de los diez años que para la «extinción de la responsabilidad» establece el artículo 13.

De otro lado, de acuerdo con las reglas generales en materia de prueba, estimo que es de la incumbencia del actor probar que, en su caso, las materias primas agrarias y ganaderas y los productos de la caza y de la pesca han sufrido transformación inicial; no ya sólo porque el demandante, en esta hipótesis, pretende la inclusión de un "producto» dentro del ámbito de la Ley, sino también porque el demandado no puede soportar la prueba de un hecho negativo (que los bienes en cuestión no han sufrido esa transformación inicial).

\section{c) Lo que el perjudicado no tiene que probar}

Como consecuencia de todo lo anterior, debe entenderse que no corresponde al perjudicado probar ninguno de los siguientes extremos, hasta ahora — aunque en diferente medida - relevantes a la hora de enjuiciar la responsabilidad del fabricante:

i) En primer lugar, no le incumbe la prueba de la culpa del fabricante, si bien en este punto la doctrina jurisprudencial le venía relevando también de esa carga en virtud de la conocida inversión del onus probandi. Aunque más adelante volveré sobre este extremo, no está de más señalar ahora que, por muy grandes que han venido siendo las facilidades que los tribunales han dado a los demandantes en punto a la prueba de la culpa del fabricante, media una gran distancia entre eso y el no tener que plantear la dialéctica del pleito sobre la base de que si el producto causó el 
daño fue porque el demandado incurrió en culpa. Lo que no impide advertir, como lo ha hecho la doctrina más solvente 6 , que aunque la víctima no tiene que probar ninguna culpa, la responsabilidad del fabricante se descarta en los casos - taxativamente establecidos en la Ley - en que puede probar su falta de culpa.

ii) En segundo término, no le corresponde probar la causa del defecto $^{7}$.

iii) En tercer lugar, tampoco tiene que probar que la falta de seguridad del producto existía ya en el momento en el que fue puesto en circulación; por el contrario, incumbe al fabricante la demostración de este extremo, a tenor del artículo 6.1.b). En la doctrina italiana, muy acertadamente a mi juicio, se conduce este extremo (el de la falta o no de seguridad del producto en el momento de su puesta en circulación) a un ámbito más amplio, como es el de la «esfera de organización del fabricante». Esto es para excluir que con el nuevo sistema pueda exonerarse de responsabilidad el fabricante demostrando que el defecto del producto fue debido a causa ajena a circunstancias sometidas a su control o propias de su «riesgo», esto es, no constitutivas de un fallo de su proceso productivo propiamente dicho ${ }^{8}$.

6 Tunc, «Le visage actuel de la responsabilité civile dans une perspective de droit comparé», en Développements récents du droit de la responsabilité civile, Zurich: Schulthess Polygraphischer Verlag, 1991, p. 27.

7 Si bien PARRA LUCÁN, «Ambito de protección de los daños por productos (sistema y naturaleza de la responsabilidad civil prevista en la Ley 22/1994)», en Iniuria, núm. 5, enero/marzo 1995 , p. 27, señala con razón que «aunque la Ley no lo exija como un requisito para estimar su pretensión, siempre que a la víctima le sea posible, la referencia a la causa concreta de defectuosidad del producto permitirá demostrar que el producto salió defectuoso de las manos del fabricante».

8 Como pone de manifiesto Di GiovanNI, comentario al artículo 8, en La responsabilità per danno da prodotti difettosi (G. ALPA y otros), Milán: Giuffrè, 1990, p. 124, antes de la entrada en vigor de la Ley italiana homónima de la española, e incluso a la luz de las más avanzadas teorías sobre la responsabilidad objetiva del fabricante, éste se vería libre de responsabilidad demostrando que el defecto del producto tuvo su origen en un sabotaje perpetrado por terceros extraños a su empresa; pero con la nueva Ley ni siquiera en tal hipótesis puede admitirse la no responsabilidad del fabricante, por cuanto responde como consecuencia de la existencia «originaria» del defecto, y no a causa de un fallo del factor humano o de las cosas de que se sirve para producir o, en términos más generales, de la organización empresarial ampliamente entendida. Puesto que en la actualidad el riesgo del fabricante no viene determinado por posibles fallos de su organización productiva, sino por la puesta en circulación del producto potencialmente (e incluso fortuitamente) defectuoso, el fabricante se encuentra también sujeto a riesgos que escapan de su control y a su previsión; es el ejemplo del sabotaje, cuando se lleva a cabo antes de ponerse el producto en circulación; no, desde luego, cuando el sabotaje fuese en momento posterior (v. gr., si terceros ajenos a la empresa introducen sustancias tóxicas en un alimento o en los envases de una bebida). 
iv) Por fin, el perjudicado no tiene que probar su diligencia en el uso del producto, porque según el artículo 9 de la Ley son el fabricante o el importador quienes deben acreditar la concurrencia de culpa del perjudicado?.

Naturalmente, la indicación de qué es lo que no tiene que probar el perjudicado conduce a lo que incumbe demostrar al fabricante. Particular importancia reviste la prueba, a cargo de este último, de que «el defecto no existía en el momento en que se puso en circulación el producto» ${ }^{10}$.

d) El «cruce» de las reglas sobre carga de la prueba. Doctrina del Tribunal Supremo sobre flexibilidad del principio «incumbit probatio». La «facilidad»o «disponibilidad» para cada parte, a efectos de prueba

Ahora bien, en reflexión que me parece oportuna no sólo en este caso, sino en cualquier otro en que se hable de «carga de la prueba», creo que debe distinguirse entre esa idea (la de carga de la prueba) y actividad probatoria (o resultado de la misma), en la medida en que las reglas legales que determinan a cuál de las partes del proceso corresponde probar constituyen una visión de las cosas a priori, no incompatible con la circunstancia de que cuando el juez resuelve lo hace en virtud del conjunto de elementos de cognición que le suministran las pruebas practicadas a instancias de las dos partes. Quiero decir que las reglas sobre el onus probandi pueden ser, y son, criterios para desestimar una pretensión si el demandante no proporciona elementos probatorios mínimos sobre los

9 En nuestra doctrina, trata sobre lo que no tiene que probar el perjudicado DíAz AlABART, «Responsabilidad civil por los daños causados por productos defectuosos» (GómEZ LAPlaZa y Díaz Alabart), Actualidad Civil, núm. 25, 1995, p. 534. Esta autora formula la propuesta de eliminar la prueba de la relación de causalidad a cargo del perjudicado, recordando que en el Anteproyecto de 1991 se preveía que el defecto, así como el nexo de causalidad entre éste y el daño, se consideraban probados en la medida en que estuviera debidamente establecido que la probabilidad de su existencia era mayor que la de su inexistencia. No obstante, esto no significa, a mi juicio, eximir de la prueba de la relación de causalidad, sino llevarla al terreno de la probabilidad estadística, extremo al que más adelante me referiré. Por su parte, PARRA LuCÁn, «Notas a la Ley 22/1994, de 6 de julio, de responsabilidad civil por los daños causados por productos defectuosos», Actualidad Civil, núm. 36 de 1995, p. 735, también se refiere a lo que el perjudicado no tiene que probar.

10 En la Ley italiana de transposición se da la circunstancia de que esta prueba liberatoria a cargo del fabricante se inserta en el artículo 8, que se corresponde con el 5 de la Ley española. Se observa que el legislador italiano ha querido poner el énfasis en este aspecto probatorio, a modo de puntualización (aunque me parece un poco redundante). Sobre la prueba que nos ocupa, incumbencia del fabricante, v. en la doctrina de aquel país Di GiovanNI, op. cit., pp. 136 ss., y Legnani, Prodotti difettosi. La responsabilità per danno, Rimini: Maggioli Editore, 1990, pp. 125 ss. 
extremos cuya prueba le corresponde, pero eso no excluye que el juzgador llegue a un convencimiento a la luz de lo que las dos partes han probado (o, en su caso, de lo que han alegado e intentado probar sin éxito). Por poner un ejemplo, si el fabricante aduce la causa de exoneración consistente en que «es posible presumir que el defecto no existía en el momento en que se puso en circulación el producto», bien puede suceder que la actividad probatoria desplegada por él al respecto sirva al juez para llegar al convencimiento sobre el hecho de que el producto es defectuoso (extremo cuya prueba corresponde al perjudicado) ${ }^{11}$.

En la misma línea de razonamiento, conviene tener presente que la combinación de las reglas sobre carga de la prueba en esta Ley puede simplificar notablemente la que al respecto incumbe al perjudicado demandante. Por ejemplo, la regla del artículo 3.2, por cuya virtud «un producto es defectuoso si no ofrece la seguridad normalmente ofrecida por los demás ejemplares de la misma serie», puede dar lugar a que el actor, al demandar, se limite sólo a alegar el defecto de fabricación, amparándose en la presunción legal de esa norma; le bastará afirmar que no se han producido daños a otras víctimas por productos de la serie a la que pertenece el que a él sí le dañó; circunstancia que, en virtud de la doctrina de la prueba de los hechos negativos, puede dar lugar a que sea el fabricante quien tenga que probar la inexactitud de la alegación del actor ${ }^{12}$.

Por otro lado, merece ser recordada la doctrina del Tribunal Supremo sobre la «relatividad» del principio procesal incumbit probatio ei qui dicit, non qui negat, en estrecha relación con la que proclama la necesidad de tener en consideración la «disponibilidad» $\mathrm{o}$ «facilidad» de una determinada prueba a cargo de una de las partes. Por ejemplo, la STS 8.3.91 tiene declarado que «si bien es cierta la vigencia de la conocida regla "incumbit probatio..." la misma no tiene un valor absoluto y axiomático, matizando la moderna doctrina el alcance del principio del "onus probandi"..., en el sentido de que incumbe al actor la prueba de los hechos normalmente constitutivos de su pretensión y al demandado, en general, la de los impeditivos o extintivos que alegue y que no puede admitirse como norma absoluta que los hechos negativos no pueden ser probados, pues pueden serlo

11 Me parece muy correcta la apreciación de GoRASSINI de que la puesta en relación de las normas constitutivas de los artículos 5 y 6 (de nuestra Ley) determina una «parcial inversión de la carga de la prueba o, mejor, una comprobación de los hechos a través de una dialéctica de cargas probatorias entre las partes del proceso» (Contributo per un sistema della responsabilità del produttore, Milán: Giuffrè, 1990, p. 256).

12 Por éste y otros ejemplos que podrían citarse, estimo también correcta la opinión de GorASSINI, op. cit., p. 256, n. 64, de que «en realidad la Ley ofrece posibilidades de aplicación por cuya virtud la carga de la prueba del defecto y del nexo causal recae exclusivamente sobre el fabricante». 
por los hechos positivos contrarios, y si los demandados no se limitan a negar los hechos constitutivos de la acción o pretensión ejercitada, sino que alegan otros impeditivos, extintivos u obstativos al efecto jurídico reclamado por el actor, tendrán que probarlos — SSTS 23.9.86 y 13.12.89$\mathrm{y}$, finalmente, que la norma distributiva de la carga de la prueba no responde a unos principios inflexibles, sino que se deben adaptar a cada caso, según la naturaleza de los hechos afirmados o negados y la disponibilidad o facilidad para probar que tenga cada parte - SSTS 18.5.88, 15.7.88, 17.6.89 y 23.9.89—». Por otro lado, hay que recordar también la doctrina jurisprudencial de que «únicamente ha de acudirse a las reglas sobre carga de la prueba cuando los hechos fundamentadores de las pretensiones deducidas por las partes no han resultado probados, independientemente de cuál de ellas haya aportado los elementos probatorios» (STS 7.2.91, que invoca la de 29.11.59). La STS 20.11.91 reitera que el onus probandi sólo entra en juego cuando hay inexistencia probatoria, pero no cuando hay demostración en los autos, supuesto en que no importa quién la haya llevado a los mismos. Además, téngase en cuenta la también reiterada doctrina jurisprudencial de que el artículo 1.214 del Código civil no contiene norma valorativa de prueba, ni autoriza a examinar la apreciada, y que sólo es invocable cuando ante la falta de prueba no se haya tenido en consideración por la Sala, mas no cuando por ésta se considere probado un hecho (STS 11.2.94, que cita muchas otras en la misma línea). La STS 24.10.94 manifiesta que «el principio de atribución de carga de la prueba que establece el citado artículo 1.214 es un principio supletorio para el caso de que las partes no hayan desarrollado actividad probatoria, dentro de sus posibilidades, según su situación y disponibilidad de medios» ${ }^{13}$.

Es particularmente digna de interés en este sentido la STS 23.6.93, dictada en una reclamación por daños derivados de la rotura de una botella, en que la Sala alude a la práctica procesal de la demandada, que denomina «de brazos caídos», no haciendo absolutamente nada en período probatorio. Es un explícito reproche a la pretensión de ampararse en los principios del onus probandi mediante la alegación de que «sea el actor el que pruebe» ${ }^{14}$. La STS 8.2.95 aludió a la actitud pasiva de la demandada, que no hizo uso de la facultad que otorga el artículo 707 de la Ley de Enjuiciamiento Civil de volver a pedir ante la Audiencia el recibimiento a prueba.

13 La STS 30.9.91 dijo, por su parte, que «el artículo 1.214 no es apto para amparar el recurso de casación, salvo en aquellos casos en que el Tribunal a quo hubiera invertido en su fallo el principio de distribución de carga de la prueba»; con las SSTS que allí se citan.

14 Esta sentencia fue comentada por BERCOVITZ en CCJC, núm. 33, pp. 863 ss. 
e) Aspectos probatorios que la norma no contempla

Es obligado tener presentes ciertos extremos que, relacionados con la prueba en juicio, no contempla la norma examinada o que, simplemente, se suscitan (en el mismo marco procesal) a la luz de otros artículos de la Ley.

i) Una «prueba» previa: la de la procedencia del producto, esto es, la de la identidad del fabricante

El artículo 5 no establece, entre los elementos de la carga probatoria del perjudicado, el relativo a la identificación, por su parte, del fabricante del producto que dice ser defectuoso y por cuya virtud demanda. No obstante, me parece que esta omisión es explicable, pues está en la raíz del derecho a ser indemnizado el que el actor demuestre la identidad de quien le ha causado el daño. No es infrecuente en la doctrina decir que entre los extremos que debe probar el demandante está la «individualización», esto es, la identificación del fabricante responsable ${ }^{15}$. Y esto es innegable, puesto que de otro modo estaría mal constituida la relación procesal por incuestionable falta de legitimación pasiva de un fabricante que no lo hubiese sido del producto causante del daño o, quizá mejor, porque el «juicio sobre el fondo» conduciría a la desestimación de la demanda al no haber acreditado el actor —en realidad- ni siquiera cómo se produjo su daño; en efecto, probar el actor que ha sufrido una intoxicación como consecuencia de la ingestión de unas galletas es acreditar un hecho irrelevante a efectos jurídicos, si no demuestra que las galletas en cuestión han sido las de tal o cual marca, esto es, de tal o cual fabricante.

Pero tampoco es el caso de entrar en el nominalismo o cuestión de palabras consistente en decir si esa «carga» de identificar al concreto fabricante del producto que causó el daño constituye o no uno de los elementos del onus probandi que incumbe al perjudicado, en el sentido procesal que atribuimos a esa expresión. Lo evidente es que constituye presupuesto inexcusable del éxito de la demanda el que el actor la dirija contra un determinado (o unos determinados) fabricantes: el que lo fue (o los que lo fueron) precisamente del producto dañoso; individualización que a todas luces corresponde hacer al perjudicado que reclama.

Ahora bien, el punto en que nos hallamos puede suscitar problemas. Me ocupo de ellos a continuación.

15 Por ejemplo, Di GiovanNi, en La responsabilità..., pp. 125 ss. 
ii) El caso del producto defectuoso cuyo concreto fabricante no consta, siendo seguro que es uno de entre varios posibles. Hipótesis que caben. Cuando el perjudicado no puede establecer la identidad del concreto fabricante: «market share liability» y doctrina del daño causado por el miembro indeterminado de un grupo

Normalmente, el perjudicado conoce la identidad del fabricante (y la puede acreditar) porque el propio producto la hace constar (desde un alimento hasta un automóvil, pasando por un aparato extintor de incendios o un juguete), bien en sí mismo, bien en su envase o envoltorio. A estos efectos, hay que estar a lo que sobre el «concepto legal de fabricante o importador» establece el artículo 4. Es de particular importancia en esa norma, en lo que respecta a la prueba que nos ocupa, el subapartado d) del apartado 1, al disponer que se entiende por fabricante, a efectos de esta Ley, «cualquier persona que se presente al público como fabricante, poniendo su nombre, denominación social, su marca o cualquier otro signo o distintivo en el producto o en el envase, el envoltorio o cualquier otro elemento de protección o de presentación». Esta norma facilita sensiblemente la «carga probatoria» que nos ocupa, aunque es claro que la infinita gama de productos propios de nuestros días, y la no menos variada forma de producirse daños con su uso o consumo, pueden convertir este objeto de prueba a cargo del demandante en una actuación nada fácil, sobre todo si se trata de productos que elaboran numerosos fabricantes y cuyos elementos de presentación son frágiles y de ordinario se destruyen en seguida por el consumidor. A este respecto puede ser instrumento probatorio inexcusable, y lo es en muchas ocasiones, la testifical de personas que vieron al perjudicado utilizar o consumir el producto $^{16}$.

En efecto, aunque la prueba de testigos es una prueba frágil, puede revestir no pequeña importancia para el perjudicado actor en extremos a veces vitales para el éxito de su demanda. Piénsese, por ejemplo, en ciertos aspectos de hecho que puede plantear la necesidad de que el demandante pruebe el defecto del objeto. Habida cuenta de la estrecha relación que existe entre la prueba de este extremo y el concepto de

16 Alcover Garau se ocupó de este problema en su obra de 1990, cit., págs 130-131, concluyendo que «en la mayoría de las ocasiones no se producirá la indefensión de la víctima y no se plantearán conflictos graves», circunstancia que a su juicio explica por qué la Directiva no establece que el perjudicado deba probar que el producto es del fabricante. Por su parte, PARRA LUCÁN, «Notas...», pág 749, presta atención al problema al que me referiré en seguida, el de daño causado por producto de fabricante no identificado; se cita la sentencia del Tribunal Supremo holandés de 9.10.92, en que se declaró la responsabilidad solidaria de todos los laboratorios demandados. 
«producto defectuoso» del artículo 3, puede ser de alto interés para el demandante probar la forma en que se utilizó el producto, a efectos de dotar de adecuado sentido (en cada caso concreto) al criterio del «uso razonablemente previsible» de la cosa que, entre otros, menciona el artículo 3.1. Recuérdese que no pocos casos de la jurisprudencia contemplan como objeto de debate la forma en que el demandante utilizó la cosa o se sirvió de ella, precisamente con el objetivo de sostener (el actor) o refutar (el fabricante demandado) un uso ajustado a su naturaleza y no impropio o extravagante. Del mismo modo, en estos pleitos suele tener particular relieve lo relativo a si el daño fue realmente consecuencia del objeto o de la acción (sobre él) de comportamientos calificables como de culpa exclusiva del perjudicado, en la tradicional acepción de estas palabras; basta traer a la memoria el caso de daños derivados de rotura de botellas conteniendo bebidas carbónicas, en el que no es infrecuente que se plantee la posibilidad de que la botella se rompiera como consecuencia de haberla dejado caer al suelo la propia víctima (sobre esto versó un aspecto de la sentencia de la Audiencia Provincial de Zaragoza de 28.12.93 ${ }^{17}$ ). Aún más, dentro de la descripción de cómo ocurrió el hecho dañoso puede plantearse la cuestión relativa a la identidad misma del producto, en el sentido de quién fue su fabricante. No me refiero, desde luego, al caso en que el propio perjudicado desconoce este extremo, sino que hablo del caso en que, sosteniendo el demandante que el producto era de una determinada marca (en definitiva, de un fabricante concreto), el demandado niega o pone en tela de juicio esta afirmación ${ }^{18}$.

En todo caso, como advierte GoRASSINI ${ }^{19}$, la pertenencia del producto a la esfera del fabricante demandado constituye objeto de la valoración del juez, lo que significa que en este punto acaso no sea justificado hablar de onus probandi, en el sentido que tradicionalmente se asigna a esta expresión.

$17 R G D, 1994$, pp. 10.302 ss.

18 Tuvo un relevante papel la prueba testifical en la STS 23.6.93, que alude a «una oportuna prueba testifical» como base de la demostración de que la botella causante de los daños explotó sin que la actora hiciera de ella una incorrecta manipulación. Por cierto, esta sentencia recuerda un famoso caso de la jurisprudencia francesa que cita AlPA (Responsabilità dell'impresa e tutela del consumatore, Milán: Giuffrè, 1975, p. 433), en el que una botella de Coca-Cola causó heridas a la propietaria de un hotel; algunos clientes declararon en el juicio que la botella explotó entre las manos de la víctima, sin que antes se hubiese observado ningún golpe debido a una incorrecta manipulación del producto. Es muy significativa la importancia de la prueba testifical en los muchos casos que en nuestra jurisprudencia se conocen de daños causados por productos pirotécnicos.

19 Op. cit., p. 252. 
Una delicada situación, susceptible de varios enfoques desde el punto de vista jurídico, se plantea cuando el perjudicado aduce que su daño se ha debido a un producto (es decir, determina con precisión de qué objeto se trata, en cuanto «género»; por ejemplo, un alimento o una medicina), pero sin poder establecer la identidad del concreto fabricante que lo ha elaborado. No es el caso en que, por no figurar en el producto la identidad del fabricante o no constar de otro modo, responde el suministrador, de acuerdo con el artículo 4.3.

En este supuesto, la experiencia judicial norteamericana nos ofrece algunos ejemplos, sobre todo en casos de «daños en serie» (los producidos por el amianto, por el «agente naranja», por el medicamento llamado DES, etc.).

El caso DES consistió en un curioso pleito, entablado por una mujer, víctima de un cáncer, contra Laboratorios Abbott. El cáncer se había debido a la absorción, por la madre de la demandante, de ese medicamento nocivo (el DES) durante el embarazo de aquélla. No siendo posible identificar exactamente a la firma farmacéutica responsable, la actora demandó a los mayores fabricantes de aquel producto que habían vendido un volumen apreciable de ese medicamento en California durante el período en que su madre lo había tomado, imputándoles la demandante la carga de establecer qué empresas demandadas no habían producido lo que su madre había absorbido. El tribunal, en sentencia de $1980^{20}$, admitió esta inversión de la carga de la prueba y condenó a todos los fabricantes de DES que no habían aportado la prueba de su inocencia, siendo la condena proporcional a la parte de mercado dominada por su medicamento en el momento de la absorción. En definitiva, se aplicó el principio que se ha dado en llamar «market share responsibility» (o «liability»), es decir, un modo convencional de establecer la cuota de responsabilidad a partir de la porción de mercado dentro del total de las ventas del producto en la zona geográfica de que se trataba. Dicho en otros términos, lo que los tribunales tuvieron en cuenta fue la participación previsible de todas las empresas demandadas en la producción del daño, en proporción a su contribución al riesgo global que la distribución del me-

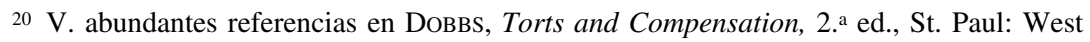
Publishing Co., 1993, pp. 743 ss. Fue el caso Sindell v. Abbott Labs., aunque hubo otros pleitos basados en los mismos antecedentes. En todos ellos, los demandantes tenían que enfrentarse con dos considerables dificultades: de un lado, la identificación del fabricante del DES ingerido en cada caso concreto; en segundo lugar, la naturaleza latente de los daños causados por el producto dio lugar a que muchas reclamaciones estuvieran afectadas por la prescripción, antes de que el daño fuese descubierto. 
dicamento había supuesto ${ }^{21}$. La justificación fundamental que adoptó el tribunal para adoptar esta decisión fue la de que establecer la responsabilidad del demandado por su cuota de mercado produce como consecuencia, a fin de cuentas, una responsabilidad para el demandado (cada uno de ellos) aproximadamente igual a los daños que ese mismo demandado causó en realidad ${ }^{22}$.

La particularidad del caso DES consistió en que hubo un gran número de posibles causantes del daño, que entraban y salían del mercado en épocas diferentes y alguno de los cuales no había tenido una larga duración; por otro lado, en muchos casos había transcurrido un largo plazo entre la ingestión del medicamento y el daño; por tanto, los demandados en este pleito no estaban en mejor posición que la demandante para identificar al fabricante del DES tomado en un caso determinado, ni existía una verdadera posibilidad real de llevar al tribunal a todos los posibles fabricantes. Finalmente, como reparo adicional a la solución del caso $D E S$, se aduce que mientras puede ser adecuado hacer uso de la «responsabilidad alternativa» en supuestos que afectan a un pequeño número de potenciales causantes del daño, la oportunidad de la fórmula desaparece

\footnotetext{
21 Se ilustra este caso en «Market share liability: an answer to the DES causation problem», nota sin firma en Harvard Law Review, 1981, pp. 668 ss. En esta nota que menciono se admite en principio el criterio adoptado por el tribunal, pero con puntualizaciones; tiene cabida - dice el autor - en la medida en que se ha demostrado que todos los demandados han sido negligentes, lo que obliga a considerar como distinto el caso en que el demandante prueba solamente que uno de los dos demandados fabricaron negligentemente el producto que causó el daño. Y se añade que en los casos de defecto de diseño todos los fabricantes que lo usan son negligentes; pero en supuestos de defecto de fabricación, sólo el fabricante que realmente elaboró el producto causante del daño ha creado el «riesgo no razonable». Advierte también el autor de la nota que en los casos DES pudo tener sentido la aplicación del «market share», porque el cáncer fue únicamente causado por el DES; pero en muchas ocasiones el daño no puede ser atribuido aisladamente a la industria en cuestión: a menudo, el producto simplemente aumenta los efectos de una perturbación «común»; y en estas hipótesis la determinación de cuál fue el «mercado» relevante puede ser difícil. Por otra parte, dado que todas las píldoras DES se consideraron igualmente dañosas en relación con el «mercado» como conjunto, el total volumen de DES comercializado correspondía exactamente con el montante o volumen de riesgo creado; pero en supuestos en los que el producto de que se trate no sea uniformemente dañoso, el total volumen vendido no se corresponderá con el daño causado, por lo que el «riesgo total» creado por cada fabricante debería establecerse en función de dos parámetros, es decir, su participación en el mercado y la «nocividad relativa» de su producto.

22 Como es lógico, la palabra «causó» significa, en el marco de la exposición, el daño que el producto de cada fabricante «pudo haber causado» al conjunto de los imaginarios consumidores, no en concreto al demandante de cada caso. En torno a la reacción doctrinal ante la teoría «market share liability», en Estados Unidos, v. DobBs, Torts..., pp. 742-751, y Epstein, Cases and Materials on Torts, 5. ${ }^{\mathrm{a}}$ ed., s. 1.: Little' Brown and Company, 1990, pp. 653-658.
} 
a medida que decrece la probabilidad de que cualquiera de los realmente demandados hubieren causado el daño ${ }^{23}$. Cuatro años más tarde del caso Sindell, el Tribunal Supremo de Wisconsin resolvió el de Collins v. Lilly \& Co. La sentencia se apartó ligeramente del criterio del tribunal de California porque entendió que cada demandado es responsable en proporción al volumen de riesgo, por él creado, de que el demandante hubiera sido dañado por el $\mathrm{DES}^{24}$.

Sin embargo, estas soluciones, por muy gratas que puedan ser a los ojos de los consumidores (sobre todo la de market share liability), no dejan de suscitar considerables reparos ${ }^{25}$. Parece que en cualquier caso pesa sobre el perjudicado demandante la carga de probar qué fabricantes,

${ }^{23}$ Fueron casos parecidos el del Smong, el Contergan-Talidomida y el Dalkon-Shield. El primero fue el de un medicamento para las enfermedades del intestino, puesto en circulación en 1934; en 1970 se detectó que el producto había causado parálisis de los miembros y ceguera en casi 10.000 japoneses. En el caso Contergan se trataba de un tranquilizante que estuvo en circulación desde 1957 hasta 1961 y que ocasionó deformaciones en brazos y piernas en niños de mujeres que lo habían tomado durante el embarazo. En el último de los casos citados, en 1971 se puso en circulación un dispositivo intrauterino, distribuyéndose a cuatro millones y medio de mujeres en todo el mundo; el producto ocasionó inflamaciones de bajo vientre y esterilidad.

24 En la sentencia Collins, el «riesgo» por el que cada demandado responde constituye una cuestión de hecho en cada caso, de suerte que las «cuotas de mercado» son relevantes para su determinación; pero cabe siempre la posibilidad de que los demandados se vean exentos de responsabilidad demostrando que su producto no pudo haber causado el daño del concreto demandante. Otro paso en esta misma orientación fue dado por el Tribunal Supremo de Washington, en el pleito Martin v. Abbott Labs. En este juicio, el tribunal declaró que a los demandados les estaba permitido liberarse de responsabilidad probando que ellos no fueron los fabricantes del DES que causó el daño al demandante, de suerte que serían los no excluidos de responsabilidad los que indemnizaran; se presumiría que han de responder en cuotas de mercado similares, hasta completar el $100 \%$, pero de suerte que cualquier demandado gozaría de la oportunidad de destruir esta presunción demostrando que su real porción de mercado era menor que la supuesta.

25 Recoge la opinión de algún sector de la doctrina norteamericana, crítica respecto a la sentencia del caso DES, CALVÃo Da SILVA, Responsabilidade civil do produtor, Coimbra: Almedina, 1990, pp. 581-582. Se ha llegado a decir de ella que «es la primera doctrina sobre la responsabilidad por productos que se funda en la riqueza más que en la responsabilidad». También se recogen críticas contra esta orientación doctrinal y jurisprudencial en DobBs y EPSTEIN, op. cit. respectivamente. Ya hemos visto antes las reservas que se formularon en la nota «Market share liability...», de la Harvard Law Review. Por otro lado, en CAmpbell, International Product Liability, Londres: Lloyd's of London Press Ltd., 1993, p. 612, se dice que la doctrina «market share liability» no tiene cabida bajo la Directiva comunitaria, pero no convence la razón que se aduce al respecto; dicen los autores que la responsabilidad según la Directiva depende del erróneo proceder de alguien (la fabricación de un producto defectuoso); a mi juicio, este argumento no es concluyente, porque constituye una premisa también en Derecho norteamericano; el problema consiste en saber quién es ese «alguien», extremo en el que la Directiva parece dejar amplio campo a las particularidades de cada ordenamiento nacional. 
dentro de los que lo fueron del producto que él genéricamente identifica, pudieron serlo de la concreta o de las concretas unidades causantes del daño ${ }^{26}$. Estimo que es fundada la opinión de CALVÃo DA SILVA ${ }^{27}$ cuando afirma que el demandante debe identificar al fabricante específico causante del daño, aunque se considere suficiente la prueba de la razonable probabilidad de que el demandado contra el que se dirige fuera el responsable en el caso de que se trate. Sostiene este autor que, delimitando con un criterio de razonabilidad y de acuerdo con las reglas de la experiencia el círculo de los posibles responsables, la presunción contra ellos (ya que estamos en el terreno de la responsabilidad por riesgo), encuentra su fundamento en el objetivo de evitar que los daños sean soportados por la víctima por el mero hecho de no poder demostrar quién los causó, así como en la circunstancia de que un fabricante cuyo producto no tuviera nada que ver con el asunto se encuentra en mejores condiciones para acreditar que él no produjo o no distribuyó el objeto dañoso en el lugar y en el tiempo en que el resultado lesivo ocurrió 28 .

26 Distinta es la hipótesis a que me referí en DE ANGEL YÁGÜEZ, «Derecho y medio ambiente», en Ciencias humanas y sociedad: la Fundación Oriol-Urquijo (1953-93), Madrid: Fundación Oriol-Urquijo, 1993, pp. 263-283, en que aludía al caso de los llamados daños medioambientales. En esta circunstancia, la solución constituida por la «pollution share liability», consistente en imputar la responsabilidad a cada elemento (fuente de contaminación) en la porción correspondiente a su «cuota de polución» (a su vez medida sobre la base de datos o cálculos extraídos del volumen de su respectiva actividad), puede ser razonable en tanto en cuanto los titulares de las empresas creadoras de esa contaminación lo hubieren sido en efecto, es decir, en atención a una hipótesis de coparticipación en la producción del daño aunque por principio no sea deliberada o dolosa-, esto es, todos han causado el perjuicio; pero no es éste el caso a que nos referimos en el texto, en el que la premisa consiste en que uno o algunos de los posibles responsables (no todos) han sido los que han puesto en el mercado el producto que concretamente ha causado el daño del demandante. Se refiere a un caso de posible contaminación causada por varios agentes por separado la STS 27.10.90.

27 Op, cit., p. 582.

28 El mismo autor acude al ejemplo, de tan frecuente cita en este problema, del paciente que con ocasión de un tratamiento prolongado sufre un daño presumiblemente causado por un medicamento defectuoso. Si el medicamento ha sido fabricado por diez laboratorios, no siendo identificable cuál de ellos elaboró las unidades tomadas por el enfermo, y éste hubiese comprado la medicina en farmacias suministradas por los diez productores, todos ellos serían responsables: el riesgo creado por cada uno de ellos es susceptible de ser la causa real y concreta de los daños, no pareciendo conforme a la razón práctica y a la razón jurídica que el perjudicado no pueda demandarles por el mero hecho de no ser individualizable el concreto fabricante. Pero si el paciente hubiese adquirido las medicinas siempre en la misma farmacia, suministrada sólo por dos fabricantes, los potenciales responsables son sólo estos últimos, pues sólo a ellos son imputables los daños producidos. Añade el mismo autor que en esta hipótesis no tendría sentido, ni se ajustaría a la teoría de la causalidad adecuada, responsabilizar a los diez laboratorios de acuerdo con sus cuotas de mercado (market share liability), dado que el riesgo abstracto creado por los otros ocho laboratorios no se materializó en el daño 
Opino que en nuestro Derecho es defendible (con las cautelas que luego diré) una solución similar, esto es, la de la responsabilidad solidaria de todos los fabricantes que, de acuerdo con la prueba suministrada por el actor, pudieron ser los que elaboraron el producto causante del daño. Desde luego, la víctima seguirá teniendo que acreditar que el daño fue consecuencia del uso o consumo de un producto determinado (más bien del consumo, puesto que en el caso de uso es poco verosímil que el producto desaparezca hasta el punto de no ser identificable su procedencia), del mismo modo que tiene que probar que fue defectuoso ${ }^{29}$. Pero una vez demostrados estos extremos, el problema de los destinatarios de su acción (en definitiva, la legitimación pasiva) - y el de la condenapueden resolverse con arreglo a los criterios doctrinales y jurisprudenciales sobre el supuesto genérico de daño causado por el miembro indeterminado de un grupo. Es decir, con la solución de la responsabilidad solidaria de todos los componentes de ese grupo.

Pesa sobre esta solución el principio clave de los sistemas clásicos de responsabilidad, es decir, el de que nadie debe responder si no ha incurrido en culpa ${ }^{30}$; $y$ en el caso que nos ocupa (léase «producto

concreto objeto de la demanda; aquí no cabe un juicio de probabilidad, sino que existe un juicio de certeza, consistente en que el producto concreto dañoso no fue elaborado por esos otros ocho laboratorios restantes. Concluye CALVÃo DA SILVA diciendo que es razonable que el riesgo de no individualización corra a cargo de quien contribuye al peligro del público y del concreto perjudicado, y no a cargo de este último. Se facilita a la víctima el planteamiento de su demanda, considerando suficiente su prueba de que los demandados son probables responsables, aunque sea con el riesgo o «precio» de que algún fabricante sea corresponsabilizado por daños (los del concreto actor) que aquél pudo no haber provocado.

CALVÃo DA Silva, op. cit., p. 587, n. 2, argumenta, además, diciendo que esta fórmula mejora a la de la market share liability, puesto que en esta última el perjudicado sufre la eventual insolvencia de uno de los fabricantes involucrados; mientras que con la tesis que propone ese riesgo se descarta, en virtud de la condena solidaria a todos los fabricantes probables productores del medicamento defectuoso.

29 Siempre, además, con la advertencia de que la hipótesis que nos ocupa revista las particularidades de cada supuesto de hecho; puesto que, por ejemplo, tomando el caso de los medicamentos, es poco verosímil que el perjudicado pueda probar en qué farmacia lo compró y en cambio no pueda acreditar la marca concreta del fármaco (pongamos por caso, conserva los envoltorios de la farmacia pero no los envases del medicamento).

${ }^{30}$ Me refiero, claro está, a culpa en relación con el concreto daño de que se habla. Porque la existencia de culpa en la actuación constituye la premisa del caso analizado. Si acudimos al ejemplo de los niños que causan daño a un miembro del grupo que «jugaba» con escopetas de aire comprimido o lanzándose piedras, el presupuesto es el de que todos ellos disparaban escopetas o tiraban piedras sin tener en cuenta el daño que podían causar. Si nos trasladamos al caso de los fabricantes (en que la culpa no entra en juego), todos ellos pusieron en el mercado un producto (el mismo) defectuoso. Precisamente por esto es por lo que el problema que tratamos se sitúa en el terreno de la relación de causalidad, no en otros (por ejemplo, en el de la $a c$ ción —no existe- o en el de la culpa — no la ha habido-). 
defectuoso» en vez de «culpa», por razones obvias), es evidente que alguno o algunos de los fabricantes posibles demandados no fueron (o pudieron no ser, que a estos efectos es lo mismo) los que pusieron en el mercado el producto concreto (en el sentido de «la unidad») causante del daño que invoca el demandante. Pero por otra parte, incluso en un sistema clásico de responsabilidad por culpa no parece un despropósito, al calor del principio pro damnato, que los tribunales apliquen esa especie de presunción de relación de causalidad a todos $\mathrm{y}$ cada uno de quienes se demuestre que pudieron ser los causantes del daño. Es evidente que esa presunción no encaja fácilmente en los dogmas tradicionales en materia de responsabilidad civil, pero tampoco debe ignorarse que la presunción de culpa y correspondiente inversión de la carga de la prueba, hoy moneda corriente en la jurisprudencia del Tribunal Supremo, constituye también una distorsión de lo que impone la interpretación conjunta de los artículos 1.902 y 1.214 del Código civil. Por otro lado, creo que en el caso que nos ocupa existe un elemento diferencial digno de gran consideración. Me refiero al hecho de que si el sistema instaurado por la Ley es de responsabilidad objetiva, es decir, por la mera puesta en circulación de un producto defectuoso, los reparos hacia la fórmula que se propone son menores. Es claro que la «indiferencia» de la culpa en un sistema de responsabilidad objetiva como el que nos ocupa no disipa la necesidad (como principio) de acreditar la identidad del presunto responsable; que en definitiva es tanto como probar la relación de causalidad, de acuerdo con la terminología clásica. Pero parece también evidente que el hecho de que un fabricante haya puesto en circulación un producto defectuoso (aunque no sea precisamente el que ha causado el daño al imaginario demandante de que hablamos) puede justificar la solución que se sugiere.

Mayores dificultades plantea la descripción de los datos de hecho que deben concurrir para que la fórmula propuesta pueda ser aplicada. Parece obvio, por una parte, que el perjudicado debe probar de forma inequívoca la identidad del producto genérico que le causó el daño; debe acreditar asimismo la identidad de los fabricantes que en la época en que adquirió el producto habían puesto el suyo en el mercado; y, por fin, deberá demandar a todos los fabricantes en quienes concurriera la circunstancia que se acaba de señalar, en la medida en que con arreglo a una diligencia razonable le fuese posible conocer sus respectivas identidades; esto, a fin de constituir válidamente la relación procesal según el criterio - a mi juicio, el único razonable para salir al paso del litisconsorcio pasivo necesario- de lo que es legítimo esperar de un demandante cuida- 
doso (diligencia exigible) en la designación de aquellos a quienes demanda ${ }^{31}$.

iii) Prueba de la identidad del fabricante del bien «unido

o incorporado» a otro bien y de la del fabricante del «elemento integrado en un producto terminado»

Según el artículo 4 de la Ley, a efectos de ésta se entiende por fabricante, entre otros, «el de cualquier elemento integrado en un producto terminado». De acuerdo con una interpretación unánime del correlativo precepto de la Directiva, el fabricante del producto terminado responde conjuntamente (de forma solidaria, en virtud del artículo 7) con el fabricante del «elemento integrado» si este último es, en sí, un «producto defectuoso» que causa el daño (o contribuye a causarlo). Por otro lado, el artículo 2.1 incluye, dentro del «concepto legal de producto» todo bien mueble, «aun cuando se encuentre unido o incorporado a otro bien mueble o inmueble». Pues bien, estas dos circunstancias obligan a plantearse

31 No me parece tan claro que, como opina PARRA LuCÁn, «The Proof of Causal Relationship-Damages Caused by Identical Products Made by Different Manufacturers (Comments on the Judgment of the Dutch Supreme Court of 9 October 1992. The possible solution offered by the Spanish legal order)», European Review of Private Law, 2, 1994, p. 424, sea posible que el perjudicado reclame sólo a uno de los laboratorios fabricantes del producto (seguimos manteniéndonos en el ejemplo del caso DES o similares), no haciéndolo contra todos los demás que hubieren distribuido el producto en la época o momento de que en cada caso se trate, esto es, todas las demás empresas que hubieran participado en el mercado en aquel período y cuya identidad fuese razonablemente cognoscible por el perjudicado. En efecto, a diferencia de lo que ocurre en el caso de producción de un daño por varios agentes, hipótesis en la que la acción contra uno de ellos es acertada (porque es seguro que ese demandado participó en la producción del resultado lesivo), en el caso en que nos encontramos se parte de la premisa de que un concreto fabricante pudo no haber sido el que elaboró las unidades determinadas de medicamento que causó el daño a la víctima. Dicho en otras palabras, si el fundamento de la eventual condena es la posibilidad de que cada fabricante presente en el mercado fuera el que dio origen al perjuicio, entiendo que es imprescindible que se demande a todos los fabricantes que hubieran tenido el producto en ese mercado. Cosa distinta es que no se pueda exigir al perjudicado (más allá de la diligencia razonablemente requerida) la «garantía» de que no deja de demandar a uno de ellos: imponer a la víctima demandante la carga de conocer a absolutamente todos los fabricantes constituye, a mi entender, una exigencia exorbitante.

Por otra parte, no me parece ningún despropósito la condena en función de la cuota de mercado, haciendo uso de una cierta analogía con el caso de sentencias que, aplicando el artículo 1.591 del Código civil, han establecido condenas a los diversos participantes en la construcción de un edificio en proporción al «beneficio» que se supone que han obtenido o podido obtener por sus respectivas actividades en la obra; es el caso, por ejemplo, de la STS 10.10.92, con distribución de porcentajes distintos entre dueño del solar, arquitecto, constructora, ayuntamiento implicado, etc. También se siguió este sistema en la STS 29.11.93 (condena a los arquitectos en un $80 \%$ y a la constructora en el $20 \%$ restante). 
de nuevo el problema de la prueba de la identidad del fabricante, prueba que como venimos diciendo incumbe al perjudicado que demanda. A ambos extremos me refiero a continuación.

Cuando un «producto terminado» causa un daño, al perjudicado le asiste la posibilidad de reclamar sólo al fabricante del "elemento integrado» cuyo carácter defectuoso hubiera dado lugar a que lo fuera el propio producto terminado, o bien la de demandar únicamente al fabricante de este último, o bien la de hacerlo contra ambos.

Empezando por la última de las tres posibilidades citadas, cuyas ventajas son innegables para el demandante (puesto que al ser dos los eventuales condenados, y además en régimen de solidaridad, se pone a cubierto de la posible insolvencia de uno de ellos), la carga probatoria a que nos venimos refiriendo (es decir, la que se refiere a la «identificación» del demandado) no parece plantear problema en lo que respecta al fabricante del producto terminado. Mayor será la dificultad, en cambio, en lo atinante a la identificación del fabricante del «elemento integrado», puesto que en muchas ocasiones puede ocurrir que el producto terminado no la revele (por ejemplo, se trata del aditivo o el conservante incorporado a un alimento). En este caso, dado que puede ser de interés para el perjudicado que su demanda se dirija también contra el fabricante del elemento integrado (como hemos dicho, para mayor garantía de la efectiva satisfacción de la indemnización), y supuesto que hubiere resultado infructuoso el intento de conocer la identidad del fabricante de la parte integrante (porque el del producto terminado no la revela), estimo que el actor podría dirigir su demanda contra el fabricante del producto terminado - que se identifica nominalmente- y contra el que lo hubiere sido de la parte integrante. Respecto a este último no cabría otra posibilidad que la de formular la demanda «contra el ignorado fabricante que hubiere producido o elaborado...». En otro caso, lo más probable es que en el curso del procedimiento contra el fabricante del producto terminado se pueda llevar a cabo el descubrimiento de la identidad del fabricante del elemento integrado, por lo que será posible al perjudicado entablar luego una acción contra este último y solicitar la acumulación de autos al amparo del artículo 161 de la Ley de Enjuiciamiento Civil.

No obstante, salvo en el caso de que sea conveniente la búsqueda de «más responsables», parece claro que esta primera posibilidad no es necesariamente la más aconsejable para el perjudicado. Demandar sólo al fabricante del producto terminado simplifica los aspectos probatorios que incumben al actor (o al menos no los complica) y, por otra parte, el perjudicado se libera de la necesidad de identificar al fabricante del elemento integrado que hubiere podido ser la causa del defecto determinan- 
te del daño; y, desde luego, le libera de la acaso más complicada prueba de que ese elemento integrado era defectuoso ${ }^{32}$.

Por ello, es razonable pensar que en estos casos la acción se dirigirá sólo contra el fabricante del producto terminado, esto es, la segunda hipótesis de las tres que he mencionado. En ella, el demandado no puede liberarse de responsabilidad argumentando que el defecto es de un elemento integrado, aun en el caso - como dice Di GIOVANNI ${ }^{33}$ - de que el propio perjudicado atribuya el defecto a un elemento integrado: el fabricante del producto terminado responde en todo caso.

La última hipótesis (primera de las que he citado más arriba) es la de que la acción se entable sólo contra el fabricante del elemento integrado. En este supuesto, además de las dificultades propias de la identificación del fabricante de ese elemento integrado en el producto final, el perjudicado se encontrará con las adicionales (y en rigor innecesarias) de demostrar que el defecto radica precisamente en ese elemento integrado y no en otro que el producto terminado pudiera tener. Parece obvio que no tiene sentido cargar con estas dificultades, disponiendo de cualquiera de las dos fórmulas anteriores. De otro lado, la eventual circunstancia de que el fabricante del elemento integrado estuviera identificado y no, en cambio, el fabricante del producto terminado, no debe constituir para el actor ninguna traba, dado que en virtud del artículo 4.3 tiene la posibilidad de demandar (como si fuera tal fabricante) a quien le hubiere suministrado o facilitado el producto ${ }^{34}$.

Por lo que respecta al caso de un bien mueble «unido o incorporado a otro bien mueble o inmueble», es preciso distinguir a su vez.

Si la incorporación es a otro bien mueble, podemos estar en presencia de un caso de incorporación de un «elemento integrado» (el que se une o incorpora) de un «producto terminado». Si la unión o incorporación es a un inmueble, y dado que este último no es «producto» a efectos de esta Ley, el objeto unido o incorporado es también en sí un «producto terminado», lo que no obsta para que a su vez pueda o puedan formar parte de él uno o varios «elementos integrados».

32 Repárese, además, en que el fabricante o importador de una parte integrante de un producto terminado no son responsables si prueban que el defecto es imputable a la concepción del producto al que ha sido incorporada o a las instrucciones dadas por el fabricante de ese producto (artículo 6.2).

33 Comentario cit., p. 127.

34 Todo lo que se dice en el texto es aplicable, desde luego, al caso de una materia prima, en virtud de lo que dispone el artículo 4.1.b) de la Ley. Con razón dice PARRA LuCÁN, «Ambito...», p. 29, que la víctima deberá tener en cuenta la circunstancia del amplio concepto legal de fabricante o importador, unida a las causas de exoneración de responsabilidad previstas en el artículo 6, a la hora de escoger a uno u otro sujeto como demandado. 
B) La prueba del defecto

Pasamos ahora a la prueba de dos de los diversos extremos a que el artículo se refiere. La del defecto es, desde luego, el extremo probatorio que más dificultades presenta.

a) Observaciones previas. La amenazadora apariencia de esta carga probatoria

La afirmación de que corresponde al perjudicado probar el defecto del producto causa un cierto estremecimiento. En efecto, la simple lectura de este pasaje del artículo mueve a pensar que, como suele decirse, se ha hecho un flaco servicio a la víctima cuando se le ha liberado de la carga de probar la culpa del fabricante. En términos prácticos tendríamos que decir que demostrar (el perjudicado) que el producto es defectuoso equivale a probar que el fabricante incurrió en culpa al elaborarlo: la propia constancia del defecto entrañaría la demostración de que el fabricante no se ajustó a los cánones de la exigencia exigible cuando llevó a cabo la producción.

De otro lado, y en estrecha relación con lo que se acaba de decir, la prueba de que el producto es defectuoso, entendida esta expresión en su más estricto significado, sería imponer al perjudicado una carga onerosísima. Tan pesada que podría decirse que con su sola formulación se está condenando al fracaso a un muy considerable número de reclamaciones. No es necesario abundar en los ejemplos, pero no está de más señalar el que ofrece un caso ya varias veces planteado ante nuestros tribunales: el de persona que resulta herida como consecuencia de la explosión de una botella conteniendo una bebida carbónica ${ }^{35}$.

Ahora bien, lo cierto es que la norma impone al perjudicado la prueba del defecto del producto. Y parece que no podía ser de otra forma,

$35 \mathrm{Si}$, como sucede muchas veces en casos de este tipo, la botella que explota se rompe en fragmentos no muy grandes, de suerte que ni siquiera es posible una prueba pericial encaminada a demostrar eventuales defectos del vidrio de la concreta unidad que se rompió, imponer a la víctima la carga de la prueba de esos defectos es atribuirle una prueba tan «diabólica» como la que solemos decir que en el Derecho romano clásico incumbía al demandante en la acción reivindicatoria. La cuestión será todavía más difícil para el perjudicado cuando se trate de un producto cuyo uso entraña una operación más o menos complicada de manipulación; es un ejemplo el caso de los productos pirotécnicos, en que frente a la innegable facilidad que ofrece al perjudicado la norma del artículo 3.2, está la circunstancia de que la víctima, si es la misma persona que ha manejado el producto, ha podido hacer de él un uso inadecuado, por torpeza o falta de experiencia; en esta hipótesis, la muy probable alegación del fabricante de que de ordinario objetos de la misma serie se utilizan sin consecuencias dañosas para nadie, origina una carga probatoria «cualificada», por así decirlo, sobre el propio perjudicado. 
porque en caso contrario no estaríamos hablando de «responsabilidad por daños causados por productos defectuosos», sino simplemente de responsabilidad por daños derivados de cualesquiera episodios en que un producto ha estado presente; o, dicho de otro modo, de acontecimientos en que un producto ha formado parte del «marco escénico» conducente al resultado lesivo ${ }^{36}$. En otros términos: no haber colocado la carga de la prueba del defecto del producto sobre los hombros del perjudicado habría constituido una extravagante e inaceptable ruptura con un elemental principio procesal del Derecho de daños; no adoptar este principio sólo tendría cabida en los contados sistemas jurídicos en que se halla establecido un régimen de indemnización de todos los accidentes con cargo a la seguridad social; y en este caso no hablamos de responsabilidad, sino de cobertura o compensación por los daños accidentales ${ }^{37}$, objetivo muy ajeno al de la Directiva y al de nuestra Ley.

\section{b) Interpretación que procede}

A pesar de esa «amenazadora apariencia» a que me refería, parece que puede afirmarse que no constituye objeto de gran dificultad determinar en qué consiste la carga probatoria del demandante en lo que se refiere al «defecto» del producto. No quiero decir con esto que los hechos que hay que probar sean siempre de fácil demostración (muy al contrario, diversas circunstancias - por ejemplo, el hecho de que el daño se produjese en la intimidad, sin testigos- pueden hacer que la prueba de lo realmente ocurrido resulte sumamente difícil); lo que quiero decir es que los extremos cuya prueba incumbe al perjudicado se pueden definir

36 Pasquau Liano, «La noción de defecto a efectos de la responsabilidad civil del fabricante por daños ocasionados por productos», Iniuria, núm. 5, enero-marzo 1995, pp. 122-123, dice: «Podrá gustar más o menos, pero no parece discutible que el artículo 5 de la nueva Ley ha querido que las dificultades probatorias en estos casos perjudiquen al demandante». A renglón seguido, el autor, después de considerar legítimo que tales dificultades se corrijan o mitiguen mediante la técnica de las presunciones, concluye - a mi juicio con todo acierto- que «en todo caso el demandante debe aportar los hechos indiciarios que, entiendo, salvo los casos en los que sea altamente improbable, por la naturaleza del producto, un uso inadecuado de la víctima, deberán ser algo más que la mera implicación del producto en el proceso de causación del daño».

37 Es inevitable la cita del tan conocido como excepcional ejemplo del sistema imperante en Nueva Zelanda. Una ley denominada Accidents Compensation Act, en vigor desde el 1.4.74 y parcialmente modificada en 1982 y 1990, establece el paso de lo que podríamos llamar un sistema tradicional de tort a otro de compensation general, es decir, de un régimen de responsabilidad a otro de indemnización. Como se ha puesto de relieve por la doctrina, se trata de «una respuesta global al problema de los accidentes», porque alcanza a todas las personas y a todos los siniestros. Este sistema, en suma, ha supuesto una auténtica eliminación de la responsabilidad civil. 
con bastante precisión. Creo que un buen punto de partida para hacer ese deslinde es el de tener presentes los extremos que el demandante no tiene que probar. No corre a su cargo, desde luego, la prueba de la culpa del fabricante. Esto es consecuencia natural del carácter de responsabilidad objetiva que en esta Ley se establece. Tampoco tiene que probar el actor la deficiencia, fallo o incorrección del proceso productivo adoptado por el fabricante. Tampoco son de su incumbencia probatoria las causas del defecto o, dicho de otro modo, las razones técnicas de su carácter defectuoso $^{38}$.

Lo que parece evidente es que el demandante tiene que acreditar el conjunto de circunstancias en las que el daño se produjo. Dicho de otro modo, tiene que probar los hechos antecedentes y coetáneos a la producción del daño que permitan al órgano judicial formarse un criterio sobre el carácter defectuoso del producto, es decir, sobre la aseveración del actor de que el producto le causó el daño. Como muy bien puntualiza Di GIOVANNI ${ }^{39}$, no se puede afirmar que el perjudicado tenga que probar el «defecto» del producto, por la sencilla razón de que esta última noción no pertenece al terreno de la prueba, sino al del «juicio». La afirmación de que existe un defecto en el producto no es fruto de una simple evidencia probatoria, sino de una valoración: esta última se resuelve en un «juicio sintético» sobre un resultado, expresado este último en términos de «seguridad». Estimo que cuando hablamos de «probar el defecto», verdaderamente tenemos que referirnos a "probar la manifestación del defecto ${ }^{40}$.

El hecho de que el demandante tenga que probar el suceso o la cadena de sucesos que condujeron al daño no es, por otra parte, ninguna particular exigencia de esta Ley (de la necesidad de probar «el defecto», según sus palabras), sino fruto de lo que en todo caso corresponde acreditar a quien demanda. Mucho más, si se nos apura, en presencia de una Ley como la comentada, gobernada por un principio de responsabilidad objetiva. Por acudir al ejemplo de la botella que estalla, antes mencionado, el

38 Di MAJO, «La responsabilità per prodotti difettosi nella Direttiva comunitaria», en $R i$ vista di diritto civile, 1989, p. 41, advierte que en beneficio del perjudicado puede sostenerse que mientras su carga principal es la de demostrar la intrínseca «inseguridad» del producto, tal y como se manifiesta en el uso al que está destinado, por el contrario no será a su cargo la demostración del vicio de proyecto o de fabricación, puesto que esto puede deducirse de la «inseguridad» del producto, de forma que se convierte en carga probatoria del fabricante demostrar lo contrario.

39 Op. cit, p. 129.

40 Di MAJo, op. cit., p. 40, dice, a mi juicio con todo acierto, que al hablar de la prueba del defecto es preciso recordar que «el defecto no es tal en sí mismo, sino en la medida en que el producto no ofrezca la seguridad que puede legítimamente esperarse de él». 
perjudicado tiene que probar las circunstancias en que la explosión se produjo, porque de otro modo llegaríamos a la absurda conclusión (desde luego no querida por la Ley ni permitida por los más elementales principios en materia de responsabilidad) de que todo dañado como consecuencia de la rotura de una botella tiene que ser indemnizado por el fabricante del producto. Precisamente por este motivo, y manteniéndonos en el mismo caso, creo que estaría condenada al fracaso la reclamación de quien habiendo sufrido daños en la cara cuando manejaba una botella (hecho que podemos dar por probado), no pudiera acreditar que la rotura del recipiente se produjo en una manipulación normal del mismo. Por decirlo de otro modo, y dado que la fractura de una botella puede ser (en abstracto) consecuencia de haberla dejado resbalar el usuario (hipótesis en la que no cabe hablar de responsabilidad del fabricante), el perjudicado corre con la carga de la prueba de que la rotura, en su concreto caso, se produjo en circunstancias que excluyen un manejo inadecuado del producto $^{41}$. Esto podrá dar lugar, sin duda, al fracaso de demandas en que los hechos que acontecieron no puedan ser demostrados por el actor; por ejemplo, porque la rotura de la botella se produjo sin testigos. Pero ese desenlace es una consecuencia que como juristas no debe extrañarnos, sabiendo como sabemos que la efectividad de los derechos se sustenta no en los hechos acaecidos, sino en los que se puede demostrar que ocurrieron $^{42}$.

Ni que decir tiene que la casuística puede ser tan variada que la alusión a los testigos que acabamos de hacer es sólo una «servidumbre» del ejemplo que hemos adoptado. Porque bien puede ocurrir que la demostración de cómo ocurrieron los acontecimientos puede liberar de todo tipo de pruebas «directas»; por ejemplo, mediante la utilización de la «indirecta» que es la de presunciones. Si, pongamos por caso, se acredita (hecho indubitado) que una persona ha fallecido electrocutada

41 Repárese en que no es lo mismo probar cómo se manejó el producto que probar que se utilizó adecuadamente, aunque lo primero puede conducir a lo segundo.

42 Sería una posible excepción a la conclusión que proponemos, siempre dentro del mismo ejemplo, el caso en el que, aun habiendo sucecido el episodio dañoso sin testigo alguno que pudiera acreditar lo acontecido, la botella rota formara parte de una serie de fabricación en la que ya hubiese habido antecedentes más o menos numerosos de fractura sin culpa del usuario; imaginemos que la rotura de envases de ese tipo y de la misma gama hubiera dado lugar a pleitos anteriores, en los que con el debido aparato probatorio se hubiese acreditado que la fractura o la explosión se produjo en circunstancias de normal utilización por parte del perjudicado: en este caso, el juzgador, por vía de presunciones (en este caso, «la experiencia»), podría llegar a la conclusión de que la rotura ocurrida sin presencia de testigos se debió al carácter defectuoso de la botella (dicho en otros términos, el juez podría deducir que no hubo un uso impropio o anormal del producto por parte del demandante del supuesto que hemos planteado). 
en el cuarto de baño, no existiendo en ese lugar otro objeto susceptible de producir descargas eléctricas que un armario metálico con iluminación (recordamos el caso de la STS 26.1.90), es razonable pensar que el demandante ha cumplido su carga probatoria con sólo acreditar las circunstancias del fallecimiento, de suerte que el juzgador pueda concluir que la muerte sólo pudo ser debida a un defecto del armario metálico en cuestión. Supongamos, por acudir a otro ejemplo que también suministra la jurisprudencia, que una persona sufre una intoxicación como consecuencia de la ingestión de un alimento (de los no excluidos por esta Ley, desde luego) en mal estado. El perjudicado no podrá probar, normalmente, el «defecto» del producto, puesto que de ordinario habrá desaparecido ya. Por ello, lo que le corresponde como carga probatoria es acreditar que ingirió ese producto determinado y las circunstancias de su intoxicación; un informe médico es apto para poner de manifiesto que la dolencia se debe a factores que, de acuerdo con los conocimientos científicos, tienen como origen una determinada descomposición o degeneración de aquel producto que se tomó. En este caso, de nuevo, parece inexcusable que sea la prueba testifical, dado el modo en que acontecen normalmente estos hechos, la que acredite la marca del producto en cuestión, esto es, su fabricante. La prueba del defecto por parte del perjudicado, en sentido estricto, es impensable ${ }^{43}$. En definitiva, y acudiendo de nuevo a la opinión de Di GIOVANNI ${ }^{44}$, se puede concluir que el perjudicado debe probar aquellos hechos materiales, «históricamente verificables», que autorizan el «juicio de defectuosidad» del producto según los criterios de valoración establecidos en el artículo 3.

\section{c) Relación con el artículo 3}

La prueba del defecto del producto conduce inexorablemente al «concepto legal de producto defectuoso» de que trata el artículo 3. No procede que entremos en el detalle de este último artículo. Pero sí es oportuno señalar que la responsabilidad objetiva del artículo 1 es, según dice su letra, por «los daños causados por los defectos de los productos...» El fabricante responde, por tanto (y como es obvio), no por el

43 Alcover Garau, La responsabilidad... (1993), p. 269, dice con acierto que «fácil es constatar que la necesidad de la víctima de probar que el defecto se ha originado en el proceso productivo del fabricante puede determinar en muchas ocasiones su indefensión de igual manera que la produce la prueba de la culpa en un régimen de responsabilidad por culpa». Por ello - añade el autor - la jurisprudencia de los distintos países tiende paulatinamente a la inversión de la carga de tal prueba.

44 Loc. cit. 
hecho de que el producto cause un daño, sino porque lo ocasione - precisamente- por su «defecto». Esta observación hacía imprescindible la definición de «concepto legal de producto defectuoso» del artículo 3, que a su vez lleva al extremo relativo a la prueba del defecto. No es necesario insistir en que el producto es defectuoso cuando «no ofrezca la seguridad que cabría legítimamente esperar, teniendo en cuenta todas las circunstancias y, especialmente, su presentación, el uso razonablemente previsible del mismo y el momento de su puesta en circulación». Por tanto, cabría la posibilidad (muy académica) de que se probara que un producto es objetivamente defectuoso, con independencia de que cause un daño o no. Pero es evidente que no es de esto de lo que se trata: el producto es defectuoso en tanto en cuanto un ejemplar determinado (no el producto en general) se manifiesta como defectuoso (es decir, se trata de un resultado), porque de hecho (precisamente en el caso enjuiciado) no ha ofrecido la seguridad que podía esperarse de él. En consecuencia, el demandante tiene sobre sí la carga de probar las circunstancias que puedan llevar al juzgador a la conclusión de que aquella concreta unidad de ese determinado producto no ofreció, de hecho, la seguridad a la que el artículo 3 se refiere.

De otro lado, y dado que el artículo 3.1 establece ciertos criterios para valorar el concepto de «seguridad que cabría legítimamente esperar» del producto, interesan en el juicio las pruebas relativas a la presentación del producto (primer criterio), al uso razonablemente previsible del mismo (segundo criterio) y al momento de su puesta en circulación (tercer criterio). Ahora bien, de estos tres elementos de juicio o aspectos relativos a la seguridad (o inseguridad) del producto, parece claro que es el primero de ellos el que mayor atención debe suscitar al perjudicado a efectos probatorios; la «presentación» del producto, de ordinario, tendrá mucho que ver con lo relativo a las instrucciones o informaciones suministradas por el fabricante. Lo que atañe al «uso razonablemente previsible» del producto irá ya probado en la «descripción histórica» de cómo ocurrieron los hechos. Y lo relativo al «momento de la puesta en circulación del producto» constituirá más bien carga probatoria del fabricante, puesto que se trata de un criterio de valoración de la «seguridad» que, de beneficiar a alguien, será justamente al fabricante, no al perjudicado.

Tiene interés también en este artículo 3, limitándonos a aspectos probatorios, el apartado 2 de dicho precepto, en el que se dispone que «en todo caso, un producto es defectuoso si no ofrece la seguridad normalmente ofrecida por los demás ejemplares de la misma serie». Desde la perspectiva de la prueba, la norma que ahora nos ocupa es favorable al perjudicado, en la medida en que establece una especie de presun- 
ción legal, aunque susceptible de prueba en contrario ${ }^{45}$. Ahora bien, aunque esta norma del apartado 2 del artículo 3 reviste para el perjudicado la condición ventajosa que acabo de señalar, me parece evidente que a la vez es arma de doble filo para la víctima, puesto que el hecho de que los demás ejemplares de la misma serie no hayan causado daños da lugar a un mayor «esfuerzo probatorio» del perjudicado en la descripción de cómo ocurrieron los hechos antecedentes y coetáneos a la producción del daño. Dicho en otras palabras, y por poner un ejemplo, si un juguete de una extensa serie no ha dado lugar a precedentes de desenlaces dañosos, el demandante (supongamos, el padre del niño que lo utilizó) tendrá que extremar los cuidados probatorios para acreditar que el niño hizo un uso del producto ajustado a lo que por normal o natural se puede entender.

Siguiendo en la hipótesis del apartado 2 del artículo 3, parece claro que corre a cargo del perjudicado la prueba de que los demás ejemplares de la serie no han ofrecido la seguridad «estadística» o «de experiencia» a que se refiere la norma; por ejemplo, invocando y demostrando antecedentes de daños de otros ejemplares de esa serie. Porque, forzoso es repetirlo, y en contra de lo que esta regla contempla, un elemento de convicción muy útil para el perjudicado puede consistir en demostrar que ese mismo producto, por definición en otras unidades, ya se ha acreditado como defectuoso. Al revés, si lo que el perjudicado pretende es atenerse a lo que el precepto dispone literalmente (no en la interpretación $a$ sensu contrario que acabo de sugerir), le bastará alegar que otros ejemplares de la misma serie no han causado daños (o lo que es lo mismo, no los han producido en términos estadísticamente significativos). Lo que ocurre es que, en este caso, la eventual (y creo que temeraria) prueba en contra por parte del fabricante (la demostración de que otros ejemplares de la misma serie han adolecido de falta de seguridad) no sólo no constituiría adecuado elemento de defensa para él -ni argumento contra lo que quiere decir la norma que examinamos-, sino que lo que haría sería robustecer la hipótesis de que el defecto del producto causante del daño no fue un defecto de fabricación, sino un defecto de diseño; en definitiva, otro defecto de los que determinan su responsabilidad.

\footnotetext{
45 Desde luego, esta prueba en contrario no puede consistir en el intento del fabricante de demostrar que no hubo culpa por su parte en el eventual carácter defectuoso del ejemplar o unidad causante del daño e integrante de la «serie» (porque ese intento de prueba contradice la regla de responsabilidad objetiva del artículo 1), sino que, de haber alguna, tendría que ser la constituida por la demostración (a cargo del fabricante) de que el daño causado por aquella concreta unidad se debió a causas ajenas al presunto defecto de la misma; por ejemplo, que el perjudicado utilizó el objeto de forma distinta a lo que es un uso «razonable» del mismo (artículo 3.1).
} 
c) La prueba del defecto de diseño: la «perfección posible»

Como es sabido, está ya muy implantada en la doctrina la distinción entre defectos de diseño, defectos de fabricación y defectos de información. Los primeros son los que hacen que un producto sea «inseguro» en su propia concepción, de suerte que el defecto afecta a todos los ejemplares de una misma gama o línea de elaboración. Defectos de fabricación son los de un producto que, perteneciendo a una gama cuyo proyecto o diseño son los adecuados, se manifiesta carente de la seguridad exigible como consecuencia de un fallo en el proceso de producción que ha afectado a uno o a unos concretos ejemplares o unidades de la serie. Y hay defecto de información cuando el producto es inseguro por falta, insuficiencia o inadecuación de las advertencias o instrucciones que el fabricante tenía que haber proporcionado o proporciona junto con el producto.

Si ahora me ocupo brevemente de la prueba del defecto de diseño es porque una interpetación judicial excesivamente amplia de esa modalidad de defecto podría conducir a la condena del fabricante en todo caso. Cabe señalar, en primer término, que no incumbe al demandante la prueba de si el defecto del producto fue de diseño o de fabricación. No obstante, sí tiene relevancia la distinción a efectos de la norma del artículo 3.2, según la cual «un producto es defectuoso si no ofrece la seguridad normalmente ofrecida por los demás ejemplares de la misma serie». Pero la cuestión tiene también importancia ante la posibilidad de que el demandante presente, en apoyo de su pretensión, pruebas de que existe un producto similar al que le causó el daño (en versión de otro fabricante, o incluso en otra gama o serie del mismo fabricante demandado), de características tales que es presumible, o incluso directamente demostrable, que no habría dado lugar al desenlace dañoso que el producto concreto objeto del pleito ocasionó. Son característicos los ejemplos referidos al automóvil que no posee un segundo retrovisor lateral, o carece de cinturones de seguridad, o cuyos elementos estructurales para caso de colisión o vuelco son menos eficaces que los de otros vehículos pareci$\operatorname{dos}^{46}$. Esta eventual prueba del perjudicado tiene que ponerse en relación con el criterio de valoración de la «seguridad» del producto a que se refiere el último inciso del artículo 3.1, es decir, el del momento de la

\footnotetext{
46 Calvão da Silva, op. cit., p. 656, insiste en el ejemplo del defecto del automóvil cuya seguridad es insuficiente para los ocupantes en la llamada «segunda colisión», es decir, el impacto que sufren dentro del vehículo en el momento inmediatamente posterior al choque; naturalmente, el fabricante no tiene obligación de diseñar un automóvil a prueba de todo accidente, pero debe proyectarlo de forma que el segundo impacto sea amortiguado y no exponga a riesgos «no razonables» en una colisión.
} 
puesta en circulación del producto. Dicho de otro modo, su resultado es un elemento de juicio para los tribunales, a efectos de una «razonable» interpretación de todo el artículo 3. Aquí se aprecia una íntima conexión entre el aspecto sustantivo (la definición de producto defectuoso) y el procesal, entendiendo por esto último lo que resulte de la prueba practicada por el demandante.

Y todo esto, en atención a que teóricamente se podría alegar por el actor una especie de «criterio de perfección posible», entendiendo por ello la idea de que todo producto es susceptible de tales mejoras o innovaciones que conduzcan, si no a la absoluta evitación de daños, sí a la de los que con más frecuencia ocasionan. Y en este punto no cabe sino remitirse al pensamiento de cada juzgador, que contemplando las circunstancias del caso y las características de cada producto, pueda adoptar como referencia para su fallo lo que debe entenderse como «seguridad razonablemente exigible» en el producto cuyo daño se enjuicie. En este sentido, es de inevitable cita el ejemplo del depósito de gasolina de una motocicleta que podría ser «totalmente» seguro contra cualquier impacto, pero de forma que su peso y su dificultad de manejo lo hiciesen totalmente inadecuado para la circulación por carretera. Como dice EPSTEIN ${ }^{47}$ dado que la absoluta perfección es inalcanzable (a la luz de los criterios de costos y ventajas), los cánones razonables (los «standards») son lo que debe tenerse en cuenta.

En esta materia, siempre dentro de los aspectos probatorios, interesa también el caso consistente en que el demandante demuestre que el fabricante demandado tomó medidas de remedio con posterioridad a un accidente, esto es, adoptó precauciones contra el riesgo por el que el demandante había sido dañado antes. STAPLETON ${ }^{48}$ señala cómo en Estados Unidos no se tuvo en cuenta esta prueba hasta comienzos de los 70 . Pero en el caso Ault v. International Havester Co. (1970), el Tribunal Supremo de California admitió esta prueba para ayudar al demandante a establecer el concepto de «defecto» en un producto; en otras palabras, el tribunal admitió el nacimiento de un producto posterior de mejor diseño para fundamentar el argumento del demandante de que esa habría sido una alternativa factible en el momento de puesta en circulación del producto que le causó el daño y, por tanto, en razón a que este producto era ya defectuoso en su origen; el tribunal argumentó que la admisión de esta prueba era un incentivo a los potenciales demandados a adoptar medidas de perfeccionamiento para reducir el riesgo de responsabilidad para accidentes futuros.

\footnotetext{
47 Op. cit., p. 671.

48 Product Liability, cit., p. 264.
} 
e) La prueba del defecto de información

Por lo que respecta al defecto de información, esto es, a la falta, insuficiencia o inadecuación de las advertencias o instrucciones dadas por el fabricante, es claro que el demandante tiene que demostrar, en el primer caso, que no existió la información que requería el uso o consumo del producto. Y en las otras dos hipótesis debe probar que las instrucciones eran insuficientes, ininteligibles, contradictorias, etc. El demandante, sin perjuicio de alegaciones o desarrollo de argumentos, puede aportar pruebas como la consistente en un informe pericial sobre riesgos de un uso no recomendable pero no advertido, comparación con lo que dicen folletos, envoltorios o envases de productos similares de otro fabricante, etc.

Pero lo que sobre todo interesa aquí, a efectos probatorios, es recoger la opinión, por ejemplo expresada por $\mathrm{CLARK}^{49}$, de que la principal ventaja de una reclamación basada en defecto de información es la de que la pretensión de que se declare que el producto es defectuoso se ve satisfecha automáticamente, sin tener que ir más lejos. En efecto, dice el autor, suele ser necesario afrontar dificultades y gastos de informes periciales si se intenta demostrar que era factible (o por el contrario que no lo era) un «diseño alternativo», esto es, distinto del que tenía el producto causante del daño. Además, el demandante puede encontrarse con dificultades para acceder a los procesos de producción y a los detalles de control de calidad del demandado. En aplicación de esta idea, el autor invoca el caso De Vito v. United Airlines Inc., en el que los pilotos sufrieron asfixia por dióxido de carbono en la cabina, lo que dio lugar a un accidente. Lo más fácil para los demandantes fue poner de relieve el deber de información sobre la necesidad de proveer de máscaras de oxígeno: fue mucho más sencillo que probar el defecto de diseño. Más aún, acreditar el defecto de información sobre los peligros inherentes al uso del producto impide la defensa del fabricante consistente en que el uso concreto que el perjudicado hizo del producto no era previsible. Por otro lado, dice el mismo autor, a veces es difícil establecer que el producto era defectuoso en el momento en que se puso en circulación o refutar reclamaciones basadas en que el daño fue debido a una modificación del producto o a cualquier otro uso indebido del mismo; el establecimiento de que esto fue consecuencia de una falta de información o de advertencias puede evitar problemas. Por último, criterio del mismo autor que me parece no desdeñable, un tribunal puede manifestarse más favorablemente dispuesto a «encontrar» defectos basados en falta de información que derivados de inadecuación del

49 Clark, Product Liability, Londres: Sweet \& Maxwell, 1989, p. 97. 
diseño o proyecto, dado que unos anuncios o impresos de escaso costo permiten al fabricante aminorar los riesgos de daño ${ }^{50}$.

\section{C) La prueba de la relación de causalidad}

La prueba de la relación de causalidad corre a cargo del perjudicado, según venimos diciendo. Pero también hemos apuntado - y ahora se insistirá en ello- que esa carga probatoria queda aliviada a través de criterios jurisprudenciales que ya nos son familiares y que sin duda operarán en la aplicación de la Ley que nos ocupa. En todo caso, debe advertirse que más que afirmar que el perjudicado debe probar la relación de causalidad, parece correcto decir que la relación de causalidad debe quedar probada; lo que no se traduce necesariamente en la imputación al actor de unos determinados modos de llevar al juez a la convicción propia del caso. La STS 3.5.95 advierte con razonable rigor que «siempre será requisito ineludible la exigencia de una relación de causalidad entre la conducta activa o pasiva del demandado y el resultado dañoso producido, de tal modo que la responsabilidad se desvanece si el expresado nexo causal no ha podido concretarse», pero obsérvese que la Sala se refiere al hecho de que la relación de causalidad no se ha probado, lo que a mi juicio no puede entenderse como una tajante declaración de que ese desenlace ha ocurrido por el simple juego del onus probandi. De otro lado, es digna de compartirse la idea de PASQUAU LIAÑO ${ }^{51}$ de que la prueba del nexo causal resulta muy fácil si se ha logrado salvar el primer escollo: si se ha evidenciado que un producto es inseguro, bastará con probar que ha sido utilizado, es decir, que el producto está implicado en el proceso de causación del daño, para que pueda considerarse que el daño se debe precisamente al

${ }^{50}$ La información defectuosa, o la no información, puede tener que ver (en lo que respecta a la prueba) con el defecto de diseño del producto. Por ejemplo, estableciendo las oportunas variantes imaginarias en torno al caso Leichtamer v. American Motors Co. (Ohio, 1981) — tomado de DoBBS, op. cit., p. 630_, podría llegarse a la misma sentencia condenatoria que allí se dictó, alegando que el fabricante no había suministrado la información adecuada para el vehículo causante del daño. Se trataba de un automóvil todo-terreno, con el que su dueño circulaba fuera de carretera asfaltada; el vehículo dio una vuelta de campana y la «barra antivuelco» (propia de este tipo de automóviles), que estaba unida al habitáculo, fabricado con un metal relativamente delgado, se desplazó hacia los pasajeros cuando el habitáculo se hundió. Un ocupante y su esposa murieron y el demandante sufrió una paraplejia. Al hecho de que el tribunal condenó al fabricante del vehículo por defecto de diseño podía unirse el argumento de que faltaba una información oportuna sobre las limitaciones de un vehículo todo-terreno para circular por cualquier lugar (se entiende, lugar con peligro de vuelta de campana); y esto, partiendo de la base de que la barra antivuelco puede ser medio de seguridad razonablemente exigible en un vehículo de ese carácter y no en un automóvil normal.

51 «La noción...», cit., p. 123. 
defecto y no a una circunstancia extrínseca o a la culpa de la víctima, a menos que así lo pruebe el fabricante ${ }^{52}$.

a) La «reducción» del problema de la causalidad al modelo estadístico: la teoría del «more probable than not»

Situar la relación de causalidad en un plano de «probabilidad» significa que los tribunales deben disponer de elementos de juicio (de ordinario extraídos de las ciencias de la Naturaleza) sobre lo que es probable o no. Hasta hace no mucho tiempo, lo habitual era que los órganos judiciales tomasen postura sobre ese «juicio de probabilidad» basándose en lo que al respecto les pudiera decir la experiencia común, aunque inspirada - eso sí- en lo que la opinión de peritos, expresada en el juicio, les pudiera hacer saber. Y todo ello, de acuerdo con un criterio de valoración de las circunstancias de cada caso, sin excesiva inclinación a «traducir» a modelos numéricos o porcentajes sus apreciaciones sobre la causa contemplada como la adecuada para la producción del resultado lesivo. Esta viene siendo, en síntesis, la posición de nuestra jurisprudencia.

Pero precisamente para estos casos, esto es, cuando es imposible esperar certeza o exactitud en materia de relación de causalidad, el juez, que puede contentarse con la mera probabilidad de su existencia, se encuentra en una posición más cómoda si esa posibilidad puede expresarse en términos aritméticos o estadísticos; en definitiva, expresados en porcentajes. Dicho de otro modo, cabe la condena del demandado - considerándose por tanto que la relación de causalidad se ha probado - cuando los elementos de juicio suministrados conducen a un «grado suficiente de probabilidad», sobre todo cuando es una probabilidad próxima a la certeza o, simplemente, una «alta probabilidad». De ahí la fórmula jurisprudencial norteamericana del more probable than not, por cuya virtud es suficiente contar con una probabilidad de más del $50 \%$ para concluir que la «causa» imputable al demandado es soporte de la relación de causalidad del caso que se enjuicia ${ }^{53}$. A una idea parecida responde la línea jurisprudencial suiza en materia de seguro de accidentes, que considera que existe una

$52 \mathrm{El}$ autor afirma que, en la práctica, será difícil diferenciar ambas operaciones (prueba del defecto y prueba del nexo causal). Más esclarecedor resulta, a su juicio, distinguir el aspecto fáctico (causalidad material) y el valorativo (causalidad jurídica o «imputación objetiva»), aspectos ambos que el propio PASQUAU desarrolla a continuación. También son interesantes las aportaciones de la doctrina norteamericana al respecto; por ejemplo, EPSTEIN, op. cit., pp. 364-385. No menos sugerente es, en el Derecho suizo, el trabajo de SCHWEIzER, La preuve de la causalité, en Développements..., cit., pp. 173-188.

53 Sobre la «prueba estadística», v. DobBs, op. cit., pp. 191-196 y 656-665, con referencias jurisprudenciales norteamericanas al respecto. 
relación exclusiva o netamente preponderante entre la actividad profesional y la enfermedad cuando la segunda es debida, al menos, en tres cuartos (por tanto, en un $75 \%$ de probabilidades) a la primera ${ }^{54}$. Es clara la posibilidad de extender este criterio «estadístico» a cualquier caso de responsabilidad civil. Asimismo, es digna de mención la corriente jurisprudencial italiana (inicialmente penal, pero hoy también civil), por cuya virtud, en materia de responsabilidad por culpa profesional sanitaria - también en este caso importa la fórmula, no el concreto ámbito de responsabilidades en que se aplica-, el criterio de la certeza de los efectos de la conducta enjuiciada puede ser sustituido por el de la probabilidad, aunque limitada, de tales efectos y de la idoneidad de esa conducta para producirlos ${ }^{55}$.

Interesa señalar que este criterio de la probabilidad estadística fue utilizado en el caso resuelto por la STS 20.2.95, en que se ventilaba la posible responsabilidad de un anestesista por haber tardado un cierto tiempo en lograr la recuperación del paciente, que había sufrido un paro cardíaco durante el curso de una intervención quirúrgica ${ }^{56}$.

54 SCHWEIzER, La preuve de la causalité, cit., p. 177.

55 Por ello, se entiende que la relación causal subsiste incluso cuando la actuación del sanitario, si se hubiere llevado a cabo correcta y tempestivamente, habría tenido no ya la certeza sino solamente serias y apreciables posibilidades de éxito, de tal forma que la vida del paciente se habría salvado con una cierta probabilidad. Así se declaró, por ejemplo, en una sentencia de casación penal de 17.1.92; se trataba de un caso en el que a una mujer que acababa de dar a luz le sobrevino una infección tetánica. Sobre la base de que los peritos informantes en el juicio dejaron sentado que un correcto y tempestivo tratamiento habría tenido un $30 \%$ de probabilidades de éxito, los médicos encartados fueron condenados. En su recurso, como es obvio, la defensa de los médicos — que no prosperó- había alegado que era absurdo afirmar que, en presencia de un $30 \%$ de posibilidades de supervivencia, nada valía el $70 \%$ restante de posibilidades de muerte aunque los profesionales hubieran actuado a tiempo.

56 Se imputaba al médico la no utilización de un desfibrilador, circunstancia que — se decía - había dado lugar a una anoxia cerebral que produjo lesiones cerebrales al paciente. Se da la circunstancia de que el Juzgado había condenado al anestesista sobre la base de que las causas de paro cardiaco son, por este orden de frecuencia, la fibrilación ventricular, la asistolia y la disociación electromecánica. Y habida cuenta que la forma de atajar la fibrilación ventricular es justamente con un desfibrilador, el no uso de este elemento por parte del médico se entendió que era la causa de la no recuperación inmediata del paciente. Pero la sentencia de la Audiencia estimó el recurso del médico, fundándose en una correcta interpretación del informe emitido en autos por un especialista en Cardiología. Ese informe acreditaba que si bien la fibrilación ventricular es la forma más frecuente de paro cardiaco en circunstancias, por así decirlo, «normales», el orden estadístico se invierte en ocasiones, para pasar a ser la asistolia la causa más frecuente de paro en el caso de enfermos sometidos a intervención quirúrgica, que era lo que ocurría en este pleito. De ahí que la Audiencia, argumentando que según la probabilidad estadística la razón del paro cardiaco no había sido la fibrilación ventricular, entendiera que el no uso del desfibrilador (se habían utilizado otros medios para atajar la parada) no constituía culpa en la actuación del profesional. Procede observar que aquí se acudió al argumento de la «estadística científica», aunque no es tan claro si fue para concluir que no había habido culpa o si lo que no había habido era relación de causalidad. A esta última interpretación conduciría la 
La misma idea de la probabilidad estadística se sigue con frecuencia en el Derecho inglés. En MILDRED ${ }^{57}$ se reconoce que el mayor problema para el demandante en muchas acciones de responsabilidad por productos será el de probar la relación de causalidad. Se advierte que tiene que demostrar que el producto era apto para causar el daño (general causation), que el daño del demandante fue en efecto causado por el uso del producto del demandado (individual causation) y que, si el defecto no hubiese existido, el demandante no habría sufrido el daño (proximate causation). En aquel país se considera como leading case en materia de causalidad (en el tort of neligence) el caso Wilsher v. Essex Area Health Authority, en el que un niño nacido prematuramente sufrió una afección incurable de la retina; esta afección podía haber sido causada por un exceso de oxígeno administrado negligentemente por los demandados, pero había otras cinco causas comunes de esa afección en prematuros ${ }^{58}$.

\section{b) Limitaciones del criterio de la probabilidad estadística}

El sistema de valoración de la prueba de la relación de causalidad sobre el modelo de «probabilidad estadística», que se acaba de mencionar, no es, sin embargo, ninguna panacea. Con independencia de las cuestiones que plantea en el orden estrictamente jurídico (por ejemplo, ¿cómo se determina qué es una frecuencia dotada de «razonable probabilidad»?, ¿sirve un mismo porcentaje de probabilidad numérica para llegar en todo caso a una convicción fundada de verosimilitud?), pesa sobre ese procedimiento toda la relatividad propia de «verdades científicas» sujetas a discrepancias y, por eso mismo, en continua evolución. STAPLETON ${ }^{59}$ aporta unos datos que producen un cierto desaliento en relación con la fiabilidad de la estadística médica. Señala que en un amplio estudio realizado por la Asociación Californiana del Corazón se puso de relieve que cuando un grupo de cinco cardiólogos examinaron los expedientes de 319 víctimas de ataques cardiacos, hubo una división de opiniones de tres a dos en la mayor parte de los casos y sólo en 47 hubo acuerdo; más alarmante todavía

siguiente reflexión: la actuación del médico no fue causa de la no recuperación de la actividad del corazón; pero también es cierto que cabe este otro pensamiento: los datos estadísticos médicos acreditan que en el proceder del anestesista no hubo culpa, lo que hace que sea innecesario (más bien incongruente) plantearse el problema de la relación de causalidad.

57 MiLdred, Product Liability: Law and Insurance, Londres: Lloyd's of London Press Ltd., 1994, pp. 2-16.

58 La Cámara de los Lores entendió que el demandante debe probar que la acción negligente del demandado fue «more likely than not» la causa (o la «contribución material») de su daño. En definitiva, es la misma idea del «more probable than not».

59 StAPLeTON, Product Liability, cit., pp. 281-282. 
fue descubrir que cuando 101 de esos casos fueron sometidos de nuevo a la consideración del grupo de especialistas, sin que antes supieran ellos que ya les habían sido planteados, en el 30\% de los casos el dictamen previo de los cardiólogos fue distinto ${ }^{60}$.

\section{c) La relación de causalidad cuando se trata de un «defecto» en la información por parte del fabricante}

Los problemas de la relación de causalidad son particularmente complejos cuando lo que está por medio es el «defecto» consistente en insuficiente o inadecuada información por parte del fabricante. Es sabido que dentro del concepto de «defecto» se incluyen, tanto por la doctrina como por la jurisprudencia, el de diseño, el de fabricación y el de información. Se considera que existe este último cuando el fabricante no comunica o hace constar, de forma adecuada, las características del producto, las condiciones o instrucciones de uso (para una utilización que excluya los riesgos) o, en su caso, la peligrosidad del objeto ${ }^{61}$. Cuando

60 Cita también la autora el caso de los significativos aumentos de muerte por asma en los años 60, a causa del uso de aerosoles a presión; por lo visto, no llegó a aclararse en qué medida fue debido a la fórmula química del producto o había sido consecuencia de la forma indebida en que los pacientes habían utilizado la terapia. Menciona también STAPLETon el caso Loveday, en que se valoró la prueba sobre ciertas reacciones adversas a la vacuna contra la difteria, el tétanos y la tosferina; el tribunal concluyó que el demandante no había establecido en el «balance de probabilidades» que su severo daño cerebral permanente hubiera sido causado por la vacuna más que por otra causa. La autora, con razón, señala que los ejemplos del asma y de la vacuna ponen de manifiesto que el problema básico en los casos de «causalidad» médica es el de que en las reacciones negativas puede estar implicado más de un posible agente «culpable». Por cierto, se refiere STAPLETON a las grandes cantidades de dinero gastadas para determinar la causa médica de los daños en el llamado «caso del aceite de colza» ( «spanish cooking oil»), puesto que todavía no es seguro si los efectos secundarios fueron causados por la adulteración del aceite o por residuos del pesticida que había en las verduras a las que el aceite se aplicó.

${ }^{61}$ En cuanto a este último extremo, la peligrosidad del producto, parece evidente que debe siempre considerarse en relación con el aspecto anterior (esto es, el de las instrucciones o reglas de uso), puesto que muchas veces un producto sólo es peligroso cuando no se utiliza debidamente, o se aplica a fines o funciones distintos de los que le son propios según su naturaleza; un cortacésped, por ejemplo, puede no presentar ninguna peligrosidad utilizado para su función y manipulado en la forma en que esa función se cumple, y en cambio ser peligroso si se usa como juguete. Mejor aún, cabe decir que no existe ningún producto que no pueda ser peligroso, si no se le manipula en su función natural o por persona en que sea razonable suponer suficiente destreza o, simplemente, sentido común (sería ejemplo de esto último la utilización de ciertos productos por parte de niños). De ahí que, en rigor, no sea posible distinguir entre peligrosidad y la forma de uso de cualquier objeto. Por otro lado, me parece demasiado terminante la afirmación de ORTí VALLEJo, comentario al artículo 13, en Comentarios a la Ley general para la defensa de los consumidores y usuarios (coord. Bercovitz, R. y SAlas Hernández), Madrid: Civitas, 1992, p. 423, cuando opina que la carga de la prueba del defecto de información pesa sobre el fabricante, en virtud del principio de protección del consumidor. 
se produce un daño manejando un producto en cuya presentación al público (envase, folleto de instrucciones, etc.) no se ha «agotado» por el fabricante el elenco de condiciones de uso o de advertencias de peligrosidad que sería razonable exigir ${ }^{62}$, hay que estar muy atentos a la cuestión de si esa falta o insuficiencia de información fue la causa del daño o, por el contrario, un hecho que en nada contribuyó a que el resultado lesivo se produjera; por ejemplo, porque ese resultado habría acontecido igualmente, aunque hubiese habido una exhaustiva información, vista la forma en que el producto se utilizó. Por poner un caso extremo, entre la circunstancia de no advertirse que un producto de limpieza puede ser tóxico en determinadas circunstancias, o a cierta temperatura, y el hecho de que ese producto haya sido la causa de un incendio, no existe relación de causalidad bastante para declarar la responsabilidad del fabricante si éste hizo constar en el envase la advertencia de que es inflamable cuando se hace uso de él de una forma concreta (pongamos por caso, a menos de una determinada distancia del fuego). Hace ya bastantes años, Alpa ${ }^{63}$ ilustraba esta cuestión con casos tomados del Derecho norteamericano.

62 Esta idea de lo que es razonable esperar en el terreno de la información tiene gran importancia, a mi juicio, porque hay instrucciones que, de puro obvias, no se pueden exigir al fabricante: la manipulación violenta de un tenedor puede hacer de éste un objeto muy peligroso (basta recordar algún caso de nuestra jurisprudencia, de manejo de ese objeto por un niño, con resultados lamentables); pero parece fuera de toda duda que el fabricante de ese producto no incurre en defecto de información si no lo advierte.

63 AlPa, Responsabilità..., p. 431. Señalaba cómo en las hipótesis en que el objeto es idóneo para su uso, si no ha sido dotado de instrucciones y advertencias necesarias, el consumidor tendría que demostrar la existencia de un nexo de causalidad entre el defecto de información y el daño sufrido: se trataría de probar que el daño no se habría producido si el producto hubiese estado acompañado de todas aquellas indicaciones que son necesarias para un uso inocuo. Entre los warning cases que el autor mencionaba estaba el caso Jacobs v. Technical Chemical Co., de Texas, 1971. El demandante tenía en su automóvil una lata de aceite lubricante; expuesta a la presión del aparato de aire acondicionado instalado en el vehículo, la lata explotó, provocando serios daños al conductor. El jurado entendió que el producto debía considerarse «unreasonably dangerous» por el hecho de que no estaba provisto de informaciones idóneas que advirtiesen al usuario sobre la conservación de la lata en condiciones especiales.

En otras ocasiones se admitió una auténtica strict liability, sin tener en cuenta la posible culpa concurrente de la víctima. Un ejemplo en este sentido fue el del caso McKisson v. Sales Applicates Inc. La demandante había usado una loción que contenía un ácido no adaptado a todos los tipos de cabellos; a pesar de que las instrucciones unidas al embalaje del producto contenían claramente el aviso de no emplear la loción sino en los concretos casos en los que era inocua, la actora lo usó. El haber adjuntado esas instrucciones no se consideró, sin embargo, causa suficiente de exclusión de responsabilidad, puesto que el producto fue considerado también «unreasonably dangerous», y por tanto inadecuado para su puesta en circulación. 
Puede ser un caso de lo que nos ocupa el de la STS 29.5.93. La demandante había comprado en el establecimiento de una de las demandadas una botella de benceno (producto envasado por la otra demandada), que iba a utilizar para la limpieza de ropa; en el etiquetado del producto se decía que era inflamable y tóxico y se advertía de los riesgos derivados de su utilización, del mismo modo que existían instrucciones de uso; no obstante, no se hacía constar en la etiqueta la advertencia de «no apto para el uso doméstico». La demandante, a pesar de las advertencias de la etiqueta, manipuló la botella de benceno muy cerca de los focos de fuego de la cocina, a consecuencia de lo cual se produjo un incendio; la demanda se encaminaba a obtener la reparación de los daños sufridos por la actora (quemaduras). El Juzgado desestimó la demanda, confirmándose su sentencia por la Audiencia. El Tribunal Supremo declaró haber lugar al recurso. El primer motivo denunciaba inaplicación del artículo 26 de la Ley general para la defensa de consumidores y usuarios (LCU), que al igual que el artículo 25 fue alegado por la actora en su escrito de demanda, conjuntamente con las normas que regulan la responsabilidad extracontractual en el Código civil. La Sala Primera, después de hacer unas consideraciones sobre las nuevas disposiciones legales que, al lado de las del Código civil, se dirigen a obtener la reparación de los daños causados en el ejercicio de determinadas actividades, se refiere a la LCU y a su artículo 26, de cuya redacción dice que es «acorde con la tendencia objetivadora de la responsabilidad por introducción de la inversión de la carga de la prueba, de forma que el productor, importador, suministrador o quien facilita los productos o servicios viene obligado, para exonerarse de responsabilidad, a la prueba de una conducta diligente por su parte» ${ }^{64}$.

${ }^{64}$ Recuerda luego la Sala las SSTS 14.11 .84 y 25.3.91, cuando establecieron que «la responsabilidad civil del fabricante por los daños causados a los usuarios o consumidores de los productos que aquél elaboró habrá de basarse, bien en la negligente fabricación, con lanzamiento al tráfico comercial de una sustancia defectuosa, ora en faltas cometidas respecto de la necesaria instrucción o información; es decir, en el olvido de las indicaciones precisas para la utilización, absteniéndose de comunicar al público los peligros que el uso entraña, por lo que los daños pueden ser directamente causados por el propio producto o motivados por la carencia de instrucciones o inadecuación de las mismas en cuanto a sus cualidades, características y forma de empleo, prescindiendo de señalar las precauciones que han de adoptarse». Más adelante, la sentencia analiza el contenido, en lo que interesa, del Código alimentario español 25.5.85, para sentar la conclusión de que el benceno de este caso debía envasarse en recipientes cuyas etiquetas hicieran constar la advertencia de «no apto para el uso doméstico», que no existía en el recipiente de este pleito. La sentencia, no obstante, aprecia la existencia de culpa en la propia actora, que desatendiendo las claras y precisas instrucciones que se contenían en 
Comentando esta sentencia, PARRa LuCÁN ${ }^{65}$ dice que, si en el caso que allí se contempló, el envase hubiera omitido la prohibición de utilizar el producto cerca de un foco de fuego, sin informar que se trataba de un producto altamente inflamable, no cabe duda de que, producido el accidente doméstico, se debería afirmar una culpa causante de un daño; esto es, el carácter defectuoso del producto. Pero se pregunta: si se hubiera incluido en el envase la advertencia «no apto para uso doméstico», ¿se habría evitado el accidente? Entiende la autora que no, porque quien no atiende una prohibición clara y concreta, que no requiere ninguna interpretación («no usar cerca del fuego, producto altamente inflamable» u otra semejante) no habría dejado de usar el producto por el hecho de que incluyera la leyenda genérica de «no apto para uso doméstico». Dice más adelante PARRA LuCÁN: «A todo lo anterior hay que añadir que, aun admitiendo que la omisión de aquella advertencia hubiera favorecido siquiera de forma mínima el que la demandante hubiera adquirido el producto (cosa que no creo) y que, consiguientemente, pudiera intentar atribuírsele alguna responsabilidad ${ }^{66}$, entiendo que la culpa de la demandante, al incumplir unas advertencias claras y precisas sobre el correcto uso del producto, excluye totalmente la responsabilidad de la envasadora. El accidente puede considerarse, a mi juicio, resultado exclusivo de la actuación de la demandante. Ha sido su conducta la que lo ha provocado, interrumpiendo el posible nexo causal que pudiera haberse apreciado entre la infracción del deber de advertir "no apto para uso doméstico" y la producción del daño» ${ }^{67}$. También Bercovitz comentó esta sentencia ${ }^{68}$,

la etiqueta, procedió a la apertura de la botella cerca del fuego, motivo por el que asigna a la demandante la asunción de un $80 \%$ de los daños y perjuicios, quedando en el $20 \%$ de los mismos la condena a la fabricante demandada.

65 PARRA LuCÁn, «La responsabilidad civil de productos por defecto de información. La relevancia del incumplimiento de normas reglamentarias (comentario a la sentencia de la Sala Primera del TS de 29.5.93)», Iniuria, núm. 1, enero-marzo 1994, pp. 79 ss. y concretamente 89-93.

${ }^{66}$ Creo que con estas últimas palabras la autora se refiere a responsabilidad del fabricante, a pesar de la construcción de la frase.

${ }^{67}$ Luego, la autora argumenta esas mismas conclusiones a la luz de otros planteamientos, en concreto el basado en la distinción entre causalidad e imputación objetiva. Al concluir su comentario, PARRA LUCÁN afirma: «De alguna manera, la STS está atribuyendo a la responsabilidad civil una función punitiva de la que carece. Parece sancionar la conducta negligente y culpable de una entidad que envasa una sustancia sin cumplir la norma sobre etiquetado, pero sin que su conducta haya causado un daño. Esa función no es propia de la responsabilidad civil, que debe limitarse a afirmar la obligación de reparar los daños causados, al margen de todo reproche a la conducta del sujeto».

68 Bercovitz (R.), «Comentario a la STS 29.5.93», Cuadernos Civitas de Jurisprudencia Civil, núm. 32, pp. 673 ss. 
si bien poniendo al acento en el hecho de que sirve para recordar «que la responsabilidad objetiva no excluye la necesidad de probar el nexo causal, ni supone perseguir una seguridad a la que una persona no tenga legítimo derecho, en base a las circunstancias concurrentes». GómEZ LAPLAZA $^{69}$, por su parte, señala que esta sentencia es expresiva de la tendencia pro damnato que se observa en el Tribunal Supremo. Añade que es cierto que entre los defectos de los productos se incluyen los llamados «defectos de información», lo que ocurrió en este caso. Pero añade: "Ahora bien, una cosa es que el incumplimiento de ese deber de informar y la transgresión de la norma reglamentaria hayan supuesto negligencia, y otra que la sentencia resuelva bien el tema del nexo de causalidad» ${ }^{70}$.

Me parece muy sugestiva la pregunta que se plantean los autores citados, aunque también es cierto que cabe otro razonamiento, que suscito a efectos puramente dialécticos. Podría sostenerse (aun admitiendo que la eventual indicación «no apto para el uso doméstico» no habría impedido que la actora comprara el producto en el establecimiento) que la falta de esa indicación determina la responsabilidad del fabricante (en la modalidad de «defecto» en la información que nos ocupa), en atención al argumento de que sustraer un producto al uso doméstico (y, por tanto, reservarlo para el uso industrial) es una forma de asegurarse —el fabricante- de que ese producto va a ser utilizado

69 En Gómez Laplaza y Díaz Alabart, Responsabilidad civil..., p. 528. Esta autora, con mucho acierto, se pregunta por qué no se invocó aquí por el Tribunal Supremo el artículo 28 LCU, más favorable para la víctima (porque consagra una responsabilidad objetiva, dice), en vez del artículo 26, «basado en la culpa aunque con inversión de la carga de la prueba». Y esto, porque los «productos de limpieza» se incluyen en el artículo 28.2 LCU. GómEz LAPLAZA sugiere que la única explicación es que el artículo 28 exige «el correcto uso y consumo» del producto, cosa que aquí parece que no ha concurrido. BERCOVITZ, loc. cit., últimamente, p. 681, va más lejos y dice que esta sentencia sirve para «ejemplificar la desconfianza o prevención que el Alto Tribunal tiene frente a la responsabilidad plenamente objetiva» (se refiere a la del artículo $28 \mathrm{LCU})$.

70 La autora continúa diciendo: «No parece que haya un enlace preciso y directo entre ese defecto de información (que, por lo demás, no hubiere impedido la adquisición del producto) y el daño producido. Según las reglas del criterio humano — continúa-, el daño parece tener su origen en la inadecuada manipulación del producto en contra de las expresas indicaciones de la etiqueta, por lo que quizá pudiera pensarse en culpa exclusiva de la víctima. Cuestión diferente hubiera sido que lo que se hubiera omitido fuera la indicación sobre el carácter altamente inflamable del producto.» Poco más adelante dice: «Y, como hemos dicho, no creemos que, en este caso, aquel defecto haya producido el daño, sino posiblemente la propia conducta de la víctima», si bien puntualiza que el adverbio «posiblemente» es porque habría que tener en cuenta si la información suministrada respecto del carácter inflamable del producto era adecuada en relación, por una parte, con el uso previsible del mismo y, por otra, con las personas a las que iba destinado. 
por expertos o al menos por personas familiarizadas con bienes peligrosos, que es tanto como asegurarse de que no va a ser usado por personas presumiblemente privadas de esas cualidades de experiencia o conocimiento «técnico», como son las que en general utilizan un producto en el ámbito del hogar ${ }^{71}$.

71 Dicho de otro modo, es claro que un trabajador de una industria química puede ser descuidado en el uso del benceno y que, por el contrario, una ama de casa puede ser cuidadosísima en su utilización. Pero también parece evidente que la advertencia de que un producto no es apto para el uso doméstico (es tanto como decir para la persona corriente) constituye una forma de evitar que el ciudadano normal use del mismo, precisamente porque entraña algún peligro. En definitiva, creo que es defendible la interpretación de que la falta de esa mención, que el Tribunal Supremo echa de menos, puede ser elemento para entender que entre esa ausencia y el resultado lesivo hubo relación de causalidad. Es como si no fuera necesaria la mención de que un producto pirotécnico, por ejemplo, sólo puede ser utilizado por profesionales; no hacerse esa mención no impide que un ciudadano cualquiera lo compre, pero si la advertencia existe, la no responsabilidad del fabricante parece incontestable; del mismo modo que no parece dudoso que responderá si no existe esa indicación de ser un producto reservado al uso de profesionales. 